\title{
Auswirkungen des gesetzlichen Mindestlohnes auf die Beschäftigung und den Arbeitnehmerschutz in der Abfallwirtschaft
}

\author{
Nicole Gürtzgen • Maresa Sprietsma • \\ Michaela Niefert · Sandra Gottschalk
}

Angenommen: 13. September 2012 / Online publiziert: 6. Oktober 2012

(C) Institut für Arbeitsmarkt- und Berufsforschung 2012

Zusammenfassung Der vorliegende Beitrag liefert eine Zusammenfassung der Ergebnisse der Evaluation der Einführung des Mindestlohnes in der Abfallwirtschaft zum 01.01.2010. Die Evaluation setzt sich aus einem Branchenbild sowie einer kausalen Wirkungsanalyse des Mindestlohnes auf Basis einer Unternehmensbefragung zusammen. Auf Basis der Befragungsdaten zeigt sich, dass die Betroffenheit der Branche vom Mindestlohn mit ca. $23 \%$ der Unternehmen und $6 \%$ der Beschäftigten als gering einzustufen ist. Die Resultate der Wirkungsanalyse mit Hilfe verschiedener Kontrollgruppenansätze deuten darauf hin, dass die Einführung des Mindestlohnes innerhalb der bisherigen Geltungsdauer auf die Beschäftigung keine messbaren Effekte entfaltet hat. Bezogen auf den Arbeitnehmerschutz lässt sich als Folge des Mindestlohnes eine Tendenz zur Verdichtung der Arbeit sowie zur Zunahme ungeschützter Beschäftigungsverhältnisse feststellen.

The economic effects of a sector-specific minimum wage in the German waste management industry

\begin{abstract}
This article presents a summary of the evaluation of a sector-specific minimum wage in the German waste management industry. The study consists of two parts: first, a descriptive analysis of the sector's market conditions and, second, a causal evaluation of the minimum wage's impact on economic outcomes, such as employment and working
\end{abstract}

Für die in diesem Beitrag publizierten Ergebnisse und Schlussfolgerungen zeichnen sich ausschließlich die Autorinnen verantwortlich. Sie geben nicht notwendigerweise die Position des Bundesministerium für Arbeit und Soziales wieder.

N. Gürtzgen ( $\varangle) \cdot$ M. Sprietsma · M. Niefert · S. Gottschalk ZEW Mannheim, Mannheim, Germany

e-mail: guertzgen@zew.de conditions. The causal analysis is based upon a firm-level survey. The empirical evidence from the survey data suggests that prior to the introduction of the minimum wage only 23 per cent of employers paid wages and 6 per cent of employees received wages below the minimum wage. Difference-in-difference estimates indicate that the minimum wage had no significant impact on employment within the first year after its introduction in January 2010. With respect to working conditions, our results provide some first weak evidence of an increase in marginal employment relationships as well as effective working time.

\section{Einleitung}

Die Einführung des Arbeitnehmerentsendegesetzes (AEntG) im Jahre 1996 hat für den deutschen Arbeitsmarkt die rechtliche Grundlage gelegt, tarifvertragliche Bestimmungen per Allgemeinverbindlicherklärung oder Rechtsverordnung auf alle Beschäftigten einer Branche auszuweiten. Während das Gesetz zunächst nur das Bauhaupt- und zwei Baunebengewerbe betraf, wurden bis zum Jahre 2010 elf weitere Branchen für jeweils unterschiedliche Geltungszeiträume in das AEntG aufgenommen. Die mit dem AEntG geschaffene Möglichkeit der Einführung branchenspezifischer Mindestlöhne hat eine kontrovers geführte wirtschaftspolitische Diskussion um die möglichen Folgen von Mindestlöhnen entfacht. Die Kontroverse resultiert nicht zuletzt aus den äuBerst uneinheitlichen Ergebnissen, zu denen empirische Studien zu Mindestlohnwirkungen gelangen (für einen Überblick siehe z. B. Neumark und Wascher 2007). Verglichen mit der Vielzahl internationaler Studien gab es zu den Auswirkungen von Mindestlöhnen auf dem deutschen Arbeitsmarkt mit Ausnahme der Studie von König und Möller (2008) lange vergleichsweise wenig empirische Evidenz. 
Vor diesem Hintergrund hat das Bundesministerium für Arbeit und Soziales (BMAS) die empirische Evaluation der Wirkungen der bestehenden gesetzlichen Mindestlohnregelungen bis zum Herbst 2011 in acht Branchen in Auftrag gegeben. Der folgende Beitrag liefert eine Zusammenfassung der Ergebnisse der Evaluation der Auswirkungen des Mindestlohns in der Abfallwirtschaft, die am Zentrum für Europäische Wirtschaftsforschung (ZEW) in Zusammenarbeit mit dem Institut für angewandte Sozialwissenschaft (infas) durchgeführt wurde.

Der Mindestlohn in der Abfallwirtschaft trat per Rechtsverordnung über die Aufnahme der Abfallwirtschaft in das Arbeitnehmerentsendegesetz erstmals zum 1. Januar 2010 in Kraft. Die Einführung des Mindestlohnes wurde bereits seit 2008 zwischen den drei Tarifpartnern der Branche Verdi, dem Bundesverband der Deutschen Entsorgungswirtschaft e.V. (BDE) und der Vereinigung kommunaler Arbeitgeberverbände (VKA) insbesondere vor dem Hintergrund eines erheblichen - vor allem über die Lohnkosten ausgetragenen - Preiswettbewerbs verhandelt. Dabei wurden seitens der Tarifpartner vor allem die niedrigen Entgelte der privaten Entsorgungsunternehmen und der vermehrte Einsatz von Leiharbeitskräften beklagt, deren verstärkter Einsatz vor der Mindestlohneinführung ein wichtiges Instrument zur Kostensenkung darstellte. ${ }^{1}$ Der zwischen den drei Tarifpartnern ausgehandelte Mindestlohntarifvertrag trat schließlich zum 01.01.2010 mit einem flächendeckenden Mindestlohn in Höhe von 8,02 Euro bundesweit in Kraft. Der Mindestlohn lag somit etwas unterhalb der niedrigsten Lohngruppen des vorher gültigen Tarifvertrages TVöD-E für die kommunalen Arbeitgeber, war jedoch deutlich niedriger als die untersten Stundenentgelte des mit dem BDE ausgehandelten Tarifvertrages. ${ }^{2}$ Der Mindestlohn gilt für alle Beschäftigten der Abfallwirtschaft, d.h. auch für Leiharbeitskräfte. Der derzeit aktuelle Mindestlohntarifvertrag hat eine Laufzeit bis zum 31.12.2012 und sieht einen Mindestlohn von $8,33 €$ pro Stunde vor.

Der Mindestlohn in der Abfallwirtschaft wurde in einer Branche eingeführt, die durch eine besondere Wettbewerbssituation auf dem Gütermarkt charakterisiert ist. Die

\footnotetext{
${ }^{1}$ Vor der Mindestlohneinführung lagen die mit der Tarifgemeinschaft Christliche Gewerkschaften für Zeitarbeit und Personalserviceagenturen (CGZP) vereinbarten Stundenlöhne deutlich unterhalb der mit den Tarifpartnern der Abfallwirtschaft vereinbarten Entgelte. So lag 2009 der Stundenlohn eines in der Abfallwirtschaft tätigen Leiharbeiters in der niedrigsten Entgeltstufe in Westdeutschland bei 7,35€ und in Ostdeutschland bei $6,15 €$.

${ }^{2}$ Die unteren Lohngruppen der mit der VKA ausgehandelten Tarife vor der Mindestlohneinführung betrugen für die öffentlichen Arbeitgeber zwischen 8,38 bis zu $9,34 €$ in West- und 8,17 bis zu $9,11 €$ in Ostdeutschland. Für die tarifgebundenen privaten Arbeitgeber lag die untere Lohngruppe bei $10,53 €$ in West- und $10,02 €$ in Ostdeutschland (siehe auch Tab. $10 \mathrm{im}$ Anhang B).
}

Liberalisierung des Entsorgungsmarktes mit einem möglichen Marktzutritt von privaten Entsorgungsunternehmen wurde 1996 mit dem Kreislaufwirtschafts- und Abfallgesetz (KrW-/AbfG) eingeleitet. Die Liberalisierung betraf primär die Entsorgung gewerblicher Abfälle, während für die Hausmüllentsorgung weiterhin öffentlich-rechtliche Entsorgungsträger verantwortlich sind. Die von den öffentlichen Entsorgungsträgern organisierte Hausmüllentsorgung erfolgt getrennt für einzelne Entsorgungsgebiete und ist durch einen Anspruch der privaten Haushalte auf Entsorgung ihrer Abfälle bei gleichzeitiger Überlassungspflicht der Abfälle und einer Verrechnung der Entsorgungskosten über Gebühren gemäß dem Kostendeckungsprinzip gekennzeichnet. Die Hausmüllentsorgung wird entweder über kommunale Eigenbetriebe oder über öffentliche oder private Unternehmen inkl. öffentlich-privater Gemeinschaftsunternehmen (im Rahmen öffentlicher Ausschreibungen) durchgeführt.

Insgesamt sind Teile der Abfallwirtschaft trotz der Liberalisierung der Branche somit weiterhin durch einen eingeschränkten Wettbewerb geprägt. Aufgrund des Kostendeckungsprinzips im öffentlichen Gebührenrecht sowie der Praxis von Preisgleitregelungen können Dienstleister im Bereich der Hausmüllentsorgung ihre Kosten über die Abfallgebühren auf die Abfallerzeuger überwälzen, so dass die Anreize zu Kosteneinsparungen gering sind und es zu einer hohen Varianz der Müllgebühren zwischen den einzelnen Entsorgungsregionen kommt. Der 2010 eingeführte Mindestlohn wirkt zudem in einer Branche, die nicht nur durch eine besondere Wettbewerbssituation auf dem Gütermarkt, sondern darüber hinaus durch eine beträchtliche $\mathrm{He}$ terogenität gekennzeichnet ist. Letztere resultiert nicht nur aus der Koexistenz privater und kommunaler Anbieter, sondern spiegelt ebenfalls eine durch die Vielfalt von Kleinbis Großbetrieben charakterisierte Größenverteilung wider. Diese Heterogenität reflektiert zum Teil die Diversität der Tätigkeitsfelder der Branche, die unterschiedliche Bereiche wie die Abfallsammlung, -beseitigung, die Abfallverwertung (Rückgewinnung/Recycling) sowie die Reinigung von Verkehrsflächen umfassen. Während die Markteintrittsbarrieren aufgrund hoher Kapitalintensität und notwendigem technischen und institutionellen Wissen in Teilen der Abfallwirtschaft als hoch anzusehen sind (z. B. im Bereich des Recyclings), sind andere Tätigkeitsfelder wie z. B. die StraBenreinigung mit deutlich geringeren Markteintrittsbarrieren versehen.

Die durch Vereinbarung der Regierungsfraktionen vorgegebenen Zielgrößen der von der Auftragnehmerin durchzuführenden Evaluation waren Beschäftigung, Arbeitnehmerschutz und Wettbewerb. Im Hinblick auf die Wirkungsanalyse beschränkt sich der folgende Beitrag auf die Darstellung der Ergebnisse zur Beschäftigung und zum Arbeitnehmerschutz, da aufgrund der Kürze des Beobachtungszeitraums 
nach der Mindestlohneinführung im Januar 2010 mit geringen nachweisbaren Effekten auf die Wettbewerbsintensität zu rechnen ist. Grundsätzlich deuten theoretische Überlegungen darauf hin, dass die zu erwartenden Effekte maßgeblich von der Wettbewerbssituation auf dem Arbeits- und Gütermarkt abhängen (vgl. z. B. Borjas 2010). Eine Beurteilung der Mindestlohnwirkungen in der Abfallwirtschaft setzt somit zunächst eine umfangreiche Analyse der branchenspezifischen Konstellation auf beiden relevanten Märkten voraus. Ein erster Arbeitsschritt der Evaluation bestand daher in der Erstellung eines aktuellen Branchenbildes für die Abfallwirtschaft mit dem Ziel, die Entwicklung der Branche bis zum aktuellen Rand sowie die zugrundeliegenden Konstellationen auf dem Arbeits- und Gütermarkt darzustellen. Der zentrale Bestandteil der Evaluation umfasste die kausale Wirkungsanalyse der Einführung des Mindestlohnes. Die zentrale Leitfrage, die hierbei beantwortet werden sollte, lautete: Wie hat die Mindestlohneinführung die relevanten Zielgrößen verglichen mit einer hypothetischen Situation ohne den Mindestlohn verändert? Diese nicht beobachtbare, kontrafaktische Situation wurde im Rahmen der Evaluation durch zwei verschiedene Kontrollgruppen abgebildet, (1) durch Unternehmen einer nicht vom Mindestlohn betroffenen Branche und (2) durch nicht betroffene Unternehmen der Abfallwirtschaft, die vor der Mindestlohneinführung bereits oberhalb des Mindestlohnes entlohnt haben. Ein Kontrollgruppenansatz innerhalb der Branche hat den Vorteil, dass die Vergleichbarkeit von Treatment- und Kontrollgruppe leichter erfüllt sein sollte. Allerdings sollten bei diesem Evaluationsdesign wegen der erheblichen Heterogenität innerhalb der Branche Treatment- und Kontrollunternehmen nach Möglichkeit aus der gleichen Sparte der Abfallwirtschaft stammen. Da sich aufgrund der Datenlage zur Lohnstruktur bei Projektbeginn a-priori keine Aussagen zur unterschiedlichen Betroffenheit der Unternehmen vom Mindestlohn in den einzelnen Teilbereichen der Branche treffen ließen, wäre die Beschränkung auf einen Kontrollgruppenansatz innerhalb der Branche mit einem Risiko behaftet gewesen. Um diesem Risiko Rechnung zu tragen, hat die Evaluation ebenfalls den alternativen Ansatz unter Verwendung einer Kontrollbranche ohne Mindestlohn verfolgt.

Eine zentrale Herausforderung für die Wirkungsanalyse ergab sich aus der zum Evaluationsbeginn vorliegenden Datenlage. Für Messzeitpunkte nach Einführung des Mindestlohns im Jahre 2010 standen innerhalb der Projektlaufzeit kaum amtliche Unternehmens- und Beschäftigtendaten zur Verfügung. Zur Schließung dieser Datenlücke wurde daher eine repräsentative telefonische Befragung bei Unternehmen der Abfallwirtschaft durchgeführt, die für netto 492 Fälle Kennziffern für die Zielgrößen Beschäftigung, Arbeitnehmerschutz und Wettbewerbsfähigkeit erfasst hat. Für die Umsetzung des Kontrollbranchenansatzes wurden zudem netto 260 Unternehmen der ausgewählten Kontrollbranche, des Garten- und Landschaftsbaus, befragt. Damit eine erste Differenz entlang der Zeitachse gebildet werden kann, wurden die entsprechenden Größen nicht nur für den Zeitpunkt der Erhebung, sondern auch retrospektiv erhoben.

Der folgende Beitrag ist wie folgt strukturiert. Abschnitt 2 geht detaillierter auf die Umsetzung des Evaluationsauftrages im Hinblick auf die Datenlage und den verwendeten Kontrollgruppenansatz ein. Abschnitt 3 zeichnet die Entwicklung der Abfallwirtschaft sowie der ausgewählten Kontrollbranche bis zum aktuellen Rand, d.h. bis kurz vor der Einführung des Mindestlohnes nach. Abschnitt 4 stellt das quantitative Ausmaß der Betroffenheit der Branche auf Basis der für die Evaluation erhobenen Unternehmensdaten dar. In Abschn. 5 werden die zentralen Hypothesen zu den erwarteten Mindestlohnauswirkungen vor dem Hintergrund der spezifischen Güter- und Arbeitsmarktkonstellation der Branche diskutiert. Abschnitt 6 widmet sich der kausalen Wirkungsanalyse auf die Zielgrößen Beschäftigung und Arbeitnehmerschutz. Abschnitt 7 schließt mit einer Zusammenfassung und einem Ausblick auf potenzielle zukünftige Evaluationsvorhaben.

\section{Umsetzung der Evaluation}

\subsection{Evaluationsmethode}

Die Beantwortung der zentralen Leitfrage der Evaluation, in welchem Ausmaß die Mindestlohneinführung die relevanten Zielgrößen verglichen mit einer hypothetischen Situation ohne Mindestlohn verändert hat, erfordert jeweils eine Messung der Zielgrößen in einer Situation mit und ohne Mindestlohn. Da die Ausprägung der Zielgrößen in solch einer hypothetischen Situation naturgemäß nicht beobachtet werden kann, besteht ein üblicher Ansatz darin, die nach Einführung des Mindestlohns nicht messbare, kontrafaktische Situation der Zielgrößen in einer Situation ohne Mindestlohn mittels einer Kontrollgruppe beobachtbar zu machen. Diese Kontrollgruppe sollte der „Treatmentgruppe" (also den vom Mindestlohn betroffenen Unternehmen bzw. Beschäftigten) möglichst ähnlich sein. Die Wirkungen des Mindestlohnes können dann durch ein Differenzenin-Differenzen-Design (kurz: DiD-Design) abgeschätzt werden, bei dem die Differenzen der Zielgrößen der vom Mindestlohn betroffenen Unternehmen oder Individuen vor und nach der Mindestlohneinführung mit der Differenz der Zielgrößen der Unternehmen oder Individuen in der Kontrollgruppe verglichen werden. Zeitkonstante Unterschiede zwischen den beiden Gruppen werden dabei ebenso herausgefiltert wie saisonale und/oder konjunkturelle Einflüsse, welche die Gruppen in gleichem Maße betreffen. Der kausale Effekt kann somit unter der Annahme identifiziert werden, dass die Veränderungen über die Zeit in beiden Gruppen parallel ver- 
Tab. 1 Kontrollgruppenansätze im Überblick

\begin{tabular}{lll}
\hline Ansatz & Treatmentgruppe & Kontrollgruppe \\
\hline A1 & Betriebe der Abfallwirtschaft mit mind. einem & Betriebe einer geeigneten Kontrollbranche \\
A2 & Beschäftigten, der aufgrund des Mindestlohns eine & Betriebe der Abfallwirtschaft ohne Beschäftigte, die \\
& Lohnerhöhung erhielt & aufgrund des Mindest-lohns eine Lohnerhöhung erhielten \\
\hline
\end{tabular}

laufen wären, wenn der Mindestlohn nicht eingeführt worden wäre. ${ }^{3}$

Grundsätzlich hängt die Möglichkeit eine geeignete Kontrollgruppe zu identifizieren von den Umständen der Mindestlohneinführung ab. So nutzen eine Reihe empirischer Studien eine regionale Variation der Mindestlohneinführung aus. Beispiele sind die Untersuchungen von Card (1992) und Neumark und Wascher (1992), deren Kontrollgruppenkonstruktion darauf basiert, dass der Mindestlohn in verschiedenen Bundesstaaten zu unterschiedlichen Zeitpunkten oder in unterschiedlicher Höhe eingeführt wurde. Damit können Unternehmen bzw. Beschäftigte derselben Branche aus einem vom Mindestlohn nicht oder weniger betroffenen Bundesstaat als Kontrollgruppe fungieren.

Im vorliegenden Fall der Mindestlohneinführung in der Abfallwirtschaft in Deutschland wurde der Mindestlohn zeitgleich für alle Betriebe und selbstständigen Betriebsabteilungen der Branche wirksam. Es gibt somit keine Unternehmen der Abfallwirtschaft, für die die gesetzlichen Mindestlohnregelungen prinzipiell keine Gültigkeit haben. Möglich ist hingegen weiterhin ein DiD-Ansatz, wenn es trotz der zeitgleichen und bundesweiten Einführung gelingt, eine geeignete Kontrollgruppe zu identifizieren. Hierzu sind im Folgenden zwei Ansätze denkbar. Erstens kann eine Kontrollgruppe aus Unternehmen einer anderen, möglichst ähnlichen Branche rekrutiert werden (siehe Ansatz A1 in Tab. 1). Zweitens besteht die Möglichkeit - ähnlich wie in Katz und Krueger (1992) - eine Kontrollgruppe innerhalb der Abfallwirtschaft selbst zu identifizieren, indem die Variation in der tatsächlichen Betroffenheit von Unternehmen gemessen an der mindestlohnbedingten Lohnveränderung genutzt wird (Ansatz A2). Dies ist möglich, da der branchenspezifische Mindestlohn Unternehmen, die unterschiedliche Entlohnungsstrukturen aufweisen, in unterschiedlichem Maße betreffen sollte.

Die Eignung beider Ansätze für die Abschätzung der kausalen Wirkungen des Mindestlohns erfordert grundsätzlich die Überprüfung der zentralen Annahme der parallelen Trends der Treatment- und Kontrollgruppe. Eine weitere Voraussetzung für die Anwendbarkeit eines DiDAnsatzes besteht in der Nicht-Beeinflussung der Kontrollgruppe durch die Einführung des Mindestlohnes. Die Vali-

${ }^{3}$ Eine einführende Darstellung des im Folgenden angesprochenen Schätzverfahrens findet sich in Cameron und Trivedi (2005). dität dieser Annahme ist fraglich, wenn so genannte Spillovereffekte zu Abhängigkeiten zwischen der Treatmentund Kontrollgruppe führen. Dabei sind je nach Ansatz unterschiedliche Spillovereffekte entscheidend. So ist denkbar, dass negative Beschäftigungs- und Outputeffekte in der Treatmentgruppe über die Anpassung der Gütermarktpreise ebenfalls zu Anpassungen der Beschäftigung in der Kontrollgruppe führen. Dies betrifft in Tab. 1 sowohl den Ansatz auf der Branchenebene (A1) als auch den Kontrollgruppenansatz (A2) innerhalb der Abfallwirtschaft. Die Relevanz möglicher Spillovereffekte wurde daher im Rahmen der eigenen Unternehmensbefragung erhoben, um die Validität der genannten Kontrollgruppenansätze besser einschätzen zu können. Grundsätzlich weisen beide Ansätze spezifische Vor- und Nachteile auf. So ist die Annahme der parallelen Trends innerhalb einer Branche leichter zu rechtfertigen als für eine Kontrollbranche. Spillovereffekte sind jedoch vermutlich umso stärker, je größer die produktionstechnische Nähe zwischen der Treatment- und Kontrollgruppe ist.

\subsection{Die Auswahl potenziell geeigneter Branchen für einen Kontrollgruppenansatz}

Die einleitenden Ausführungen zu den Branchenspezifika in der Abfallwirtschaft haben verdeutlicht, dass aufgrund der speziellen Wettbewerbssituation auf dem Gütermarkt die Identifikation einer geeigneten Kontrollbranche äußerst schwierig ist. Da sich unmittelbar keine andere Branche angeboten hat, die ähnliche wettbewerbliche Bedingungen aufweist, wurden im Branchenbild ergebnisoffen potenzielle Vergleichsbranchen untersucht, die zumindest ausgehend von ihren Tätigkeitsfeldern Ähnlichkeiten mit der Abfallwirtschaft aufweisen. Konkret wurden zwei Branchen analysiert: das Wach- und Sicherheitsgewerbe und der Gartenund Landschaftsbau (Galabau). Diese Auswahl basierte in erster Linie darauf, dass beide Branchen durch so genannte Multi-Produktunternehmen mit der Abfallwirtschaft verzahnt sind. Beispiele hierfür sind Unternehmen im Bereich des so genannten Facility-Managements, die häufig eine Vielzahl von Dienstleistungen der Objektbetreuung wie den Galabau, Hausmeisterdienstleistungen, Abfallbeseitigung sowie den Winterdienst und Straßenreinigungen erbringen. Insgesamt haben die Ergebnisse des Branchenbilds für die Vergleichsbranchen gezeigt, dass der Galabau im Hinblick auf bestimmte Strukturmerkmale der Abfallwirtschaft am nächsten kommt. Allerdings hat der Vergleich der 
wettbewerblichen Rahmenbedingungen und der Entwicklung von Strukturkennziffern ergeben, dass diese Branche nicht für alle Teilsegmente der Abfallwirtschaft gleichermaßen als Kontrollbranche geeignet ist. Am stärksten ist die Übereinstimmung hinsichtlich der Sparte Abfallbeseitigung. Dagegen erscheint der Galabau als Kontrollbranche für die Zweige Recycling/Rückgewinnung oder die private Hausmüllentsorgung innerhalb der Abfallbranche wenig passend. Um die Evaluation für diese Teilbereiche durchzuführen, wurde daher der Kontrollgruppenansatz innerhalb der Abfallbranche eingesetzt. In Abschn. 3 wird der Vergleich der Entwicklung zentraler Strukturmerkmale der Abfallwirtschaft mit der entsprechenden Entwicklung des Galabaus dargestellt. ${ }^{4}$

\subsection{Umsetzbarkeit des Evaluationsauftrags vor dem Hintergrund der Datenbasis}

Eine kausale Wirkungsanalyse war nicht nur aus Gründen der Kontrollbranchenauswahl erheblichen Einschränkungen unterworfen. Eine weitere Herausforderung bestand darin, dass die meisten Unternehmens- und Beschäftigtendaten für einen Messzeitpunkt nach Einführung des Mindestlohns im Jahre 2010 innerhalb des für das Projekt zur Verfügung stehenden Zeitrahmens noch nicht vorlagen. Zur Lösung dieser Datenproblematik wurde im Rahmen der Evaluation eine repräsentative telefonische Unternehmensbefragung (CATI) innerhalb von 20-minütigen Interviews bei 492 Unternehmen der Abfallwirtschaft durchgeführt, die Kennziffern für die Zielgrößen Beschäftigung, Arbeitnehmerschutz und Wettbewerbsfähigkeit erfasst. Damit eine erste Differenz entlang der Zeitachse gebildet werden konnte, wurden die entsprechenden Größen nicht nur für den Zeitpunkt der Erhebung, sondern auch retrospektiv erhoben. Die Erhebung baute auf einer im Frühjahr 2008 durch das ZEW durchgeführte Befragung von 200 Unternehmen der Abfallwirtschaft auf, die damit auch den Referenzzeitpunkt für die retrospektive Erhebung vorgab. Die im Frühjahr 2008 durchgeführte Befragung hat den Vorteil, dass sie zu detaillierten Fragen der Personal- und Lohnstruktur eine von Antizipationseffekten vermutlich weitgehend unbeeinflusste Nullmessung für die Abfallwirtschaft vor Einführung des Mindestlohns abbildet.

Neben der für die Evaluation durchgeführten Unternehmensbefragung wurden Daten der amtlichen Statistik, wie die Umsatzsteuerstatistik, die Gewerbeanzeigenstatistik, die Statistik der sozialversicherungspflichtig Beschäftigten sowie das Mannheimer Unternehmenspanel (MUP) ausgewertet. Zur Erstellung des Branchenbildes wurden zudem zehn

\footnotetext{
${ }^{4}$ In diesem Abschnitt wird der Kürze halber nur der Vergleich zwischen der Abfallwirtschaft und dem Galabau dargestellt. Die Ausführungen zum Wach- und Sicherheitsgewerbe, welches als weitere mögliche Vergleichsbranche untersucht wurde, finden sich im Evaluationsbericht Egeln et al. (2011).
}

leitfadengestützte Interviews in Unternehmen der Abfallwirtschaft und potenzieller Vergleichsbranchen sowie Expertengespräche mit ausgewählten Branchenvertreter/innen geführt. Auf die Darstellung der Ergebnisse der qualitativen Erhebung wird jedoch im folgenden Beitrag aus Platzgründen verzichtet. Details zur Abgrenzung der Abfallwirtschaft über die Wirtschaftszweigklassifikation sowie zu sämtlichen Datenquellen, auf die im folgenden Beitrag Bezug genommen wird, finden sich im Anhang B.

\section{Die Entwicklung der Abfallwirtschaft und des Galabaus bis 2009}

Im Folgenden wird zum einen die konjunkturelle Entwicklung in der Abfallwirtschaft und im Galabau nachgezeichnet. Zum anderen werden die Wettbewerbssituation beider Branchen auf dem Gütermarkt im Zeitverlauf analysiert und wesentliche Strukturmerkmale dargestellt. Auf Basis der statistischen Wirtschaftszweigklassifikation lässt sich die Abfallwirtschaft in vier Sparten untergliedern: Die Abfallsammlung und -beförderung (kurz: Abfallsammlung), die Abfallbehandlung und -beseitigung (kurz: Abfallbeseitigung), das Recycling (auch: Rückgewinnung) ${ }^{5}$ und die Beseitigung von Umweltverschmutzungen und sonstige Entsorgung (kurz: sonstige Entsorgung). Die größten Anteile am Gesamtumsatz, der sich im Jahr 2008 auf rund 30 Mrd. $€$ belief, hatten laut Umsatzsteuerstatistik 2008 die Abfallsammlung (41\%) und das Recycling (37\%), gefolgt von der Abfallbeseitigung (20\%). Die sonstige Entsorgung verfügte nur über einen Anteil von $2 \%$.

\subsection{Konjunkturelle Entwicklung}

Zur Beschreibung der konjunkturellen Situation in der Abfallwirtschaft und im Galabau wird auf die Informationen der Umsatzsteuerstatistik zu den erzielten Umsätzen zurückgegriffen. Die Umsatzentwicklung ist in der Abfallwirtschaft zwischen 2002 und 2008 deutlich positiver als im Galabau (siehe Abb. 1). Nach einem geringen Rückgang 2003 steigen die Umsätze in der Abfallwirtschaft kontinuierlich und nehmen insbesondere in den Jahren 2005 bis 2007 deutlich zu. Im Galabau weisen die Umsätze dagegen bis 2004 eine rückläufige Entwicklung auf, die teilweise auf die rezessive Entwicklung im Bauhauptgewerbe zurückzuführen ist, da ein Teil der Branche an die konjunkturelle Entwicklung im Bauhauptgewerbe gekoppelt ist (VR Info 2005). Erst 2005 setzt ein Aufwärtstrend der Umsätze ein,

\footnotetext{
${ }^{5}$ Die Verwendung beider Begriffe ist im Wesentlichen auf den Bruch in der Wirtschaftszweigklassifikation zurückzuführen (vgl. Anhang B). Im Folgenden wird der Begriff „Rückgewinnung“ explizit dann verwendet, wenn es sich ausschließlich um Daten nach der WZUmstellung handelt.
} 
Abb. 1 Umsatzentwicklung Abfallwirtschaft und Galabau (ohne Umsatzsteuer, $2002=100$ ), Deutschland. Quelle: Umsatzsteuerstatistik. Anmerkung: Branchenabgrenzung der Abfallwirtschaft 2009 nicht exakt identisch mit den Vorjahren

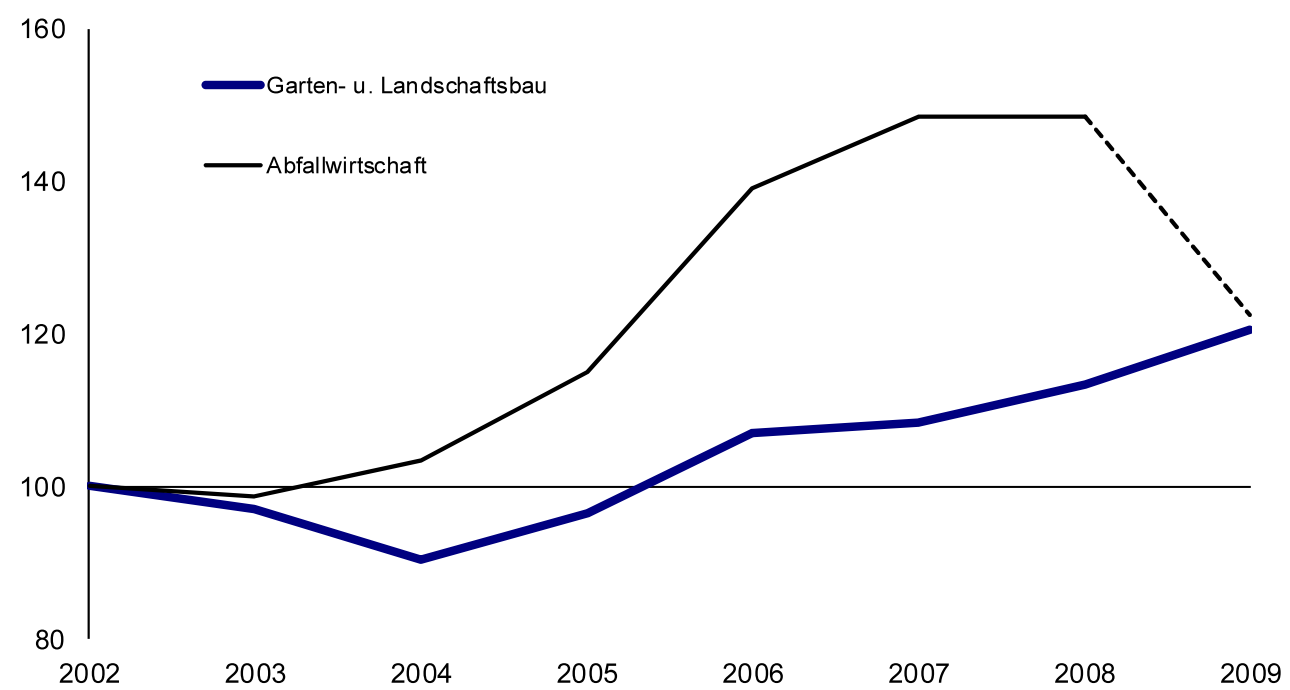

der jedoch verglichen mit der Abfallwirtschaft moderater ausfällt. Während die Umsätze in der Abfallwirtschaft zwischen 2002 und 2008 um fast $50 \%$ ansteigen, nehmen sie im Galabau nur um $13 \%$ zu. Im Jahr 2009 sind die Umsätze in der Abfallwirtschaft jedoch stark rückläufig in Folge der Ende 2008 einsetzenden Wirtschaftskrise, die einen Preisverfall bei den Sekundärrohstoffen und ein sinkendes Abfallaufkommen nach sich zog. ${ }^{6}$ Im Galabau legen die Umsätze hingegen weiter zu. Über den gesamten Beobachtungszeitraum ist das Umsatzwachstum in der Abfallwirtschaft kaum höher als im Galabau.

Eine differenzierte Darstellung der Entwicklung in den einzelnen Abfallsparten zeigt, dass der positive Umsatztrend in der Abfallwirtschaft bis 2008 vor allem durch die Sparte Recycling bestimmt ist (siehe Abb. 2). Diese verzeichnet mit über $80 \%$ einen besonders starken Umsatzanstieg zwischen 2002 und 2008. Daneben trägt ab 2005 vor allem die Sparte Abfallsammlung zum positiven Umsatztrend bei. Dort legen die Umsätze zwischen 2002 und 2008 um über $40 \%$ zu. In den Sparten Abfallbeseitigung und sonstige Entsorgung ist nach einer zunächst positiven Umsatzentwicklung hingegen ab 2007 bzw. 2008 ein Umsatzrückgang zu verzeichnen. Damit nimmt die Entwicklung der Umsätze in der Abfallbeseitigung ab 2004 einen ähnlichen Verlauf an wie im Galabau, ist ab 2007 allerdings leicht rückläufig, während sie im Galabau noch moderat zunimmt.

Von den stark rückläufigen Umsätzen im Entsorgungsgewerbe 2009 sind Branchenberichten zufolge vor allem

\footnotetext{
${ }^{6}$ Zwischen 2008 und 2009 kann die Entwicklung in der Abfallwirtschaft aufgrund der Umstellung auf die neue WZ-Systematik nicht exakt abgebildet werden (vgl. Anhang B). Sie ist in Abb. 1 daher gestrichelt dargestellt. Die Veränderungen in der Branchenabgrenzung durch die WZ-Umstellung sind jedoch als eher gering einzustufen, so dass die für 2009 dargestellte Entwicklung nicht allzu stark von der Entwicklung unter Beibehaltung der ursprünglichen Branchenabgrenzung abweichen dürfte.
}

die Recyclingwirtschaft und die Abfallbeseitigung betroffen (Finanzgruppe Branchendienst 2010). Letztere hatte mit Überkapazitäten in den Behandlungsanlagen zu kämpfen. Die besondere Betroffenheit der Recyclingwirtschaft zeigt sich auch an dem drastischen Umsatzrückgang, den die Umsatzsteuerstatistik 2009 für diese Abfallsparte ausweist, wenn man die Abgrenzungsprobleme aufgrund der WZUmstellung ignoriert. ${ }^{7}$ Demnach bricht der Umsatz beim Recycling um $30 \%$ ein. Wenn man berücksichtigt, dass sich die Recyclingsparte durch die WZ-Umstellung erweitert hat, dürfte dieser Umsatzrückgang sogar noch unterschätzt sein.

Eine besondere Betroffenheit der Sparte Abfallbeseitigung durch die Wirtschaftskrise findet sich in der Umsatzsteuerstatistik hingegen nicht bestätigt. Der leichte Umsatzanstieg, der laut der Umsatzsteuerstatistik in der Abfallbeseitigung zu verzeichnen ist, könnte allerdings Folge der breiteren Abgrenzung dieser Sparte nach der WZUmstellung sein. Rückläufige Umsätze im Jahr 2009 verzeichnen dagegen laut Umsatzsteuerstatistik die Abfallsammlung und die sonstige Entsorgung. Im Fall der Abfallsammlung ist mit Sicherheit von sinkenden Umsätzen auszugehen, da auch diese Sparte nach der WZ08 breiter abgegrenzt wird als nach der WZ03. Bei der sonstigen Entsorgung könnte der Umsatzrückgang auch Folge der Auslagerung von Tätigkeiten in andere Abfallsparten im Rahmen der WZ-Umstellung sein.

Die dynamische Umsatzentwicklung in der Recyclingsparte hat im Wesentlichen zwei Gründe. Erstens ist die Recyclingbranche innerhalb der Abfallwirtschaft am stärksten

\footnotetext{
${ }^{7}$ Die Entwicklung zwischen 2008 und 2009 in den einzelnen Abfallsparten ist mit besonderer Vorsicht zu interpretieren, weil es durch die WZ-Umstellung vor allem zu Veränderungen des Zuschnitts der Sparten (und weniger der Abfallwirtschaft insgesamt) gekommen ist und eine Darstellung der Entwicklung nach 2008 daher problematischer ist als bei Betrachtung der Abfallwirtschaft insgesamt.
} 
Abb. 2 Umsatzentwicklung Abfallsparten und Galabau (ohne Umsatzsteuer, $2002=100$ ), Deutschland Quelle: Umsatzsteuerstatistik. Anmerkung: Branchenabgrenzung der Abfallsparten 2009 nicht exakt identisch mit den Vorjahren

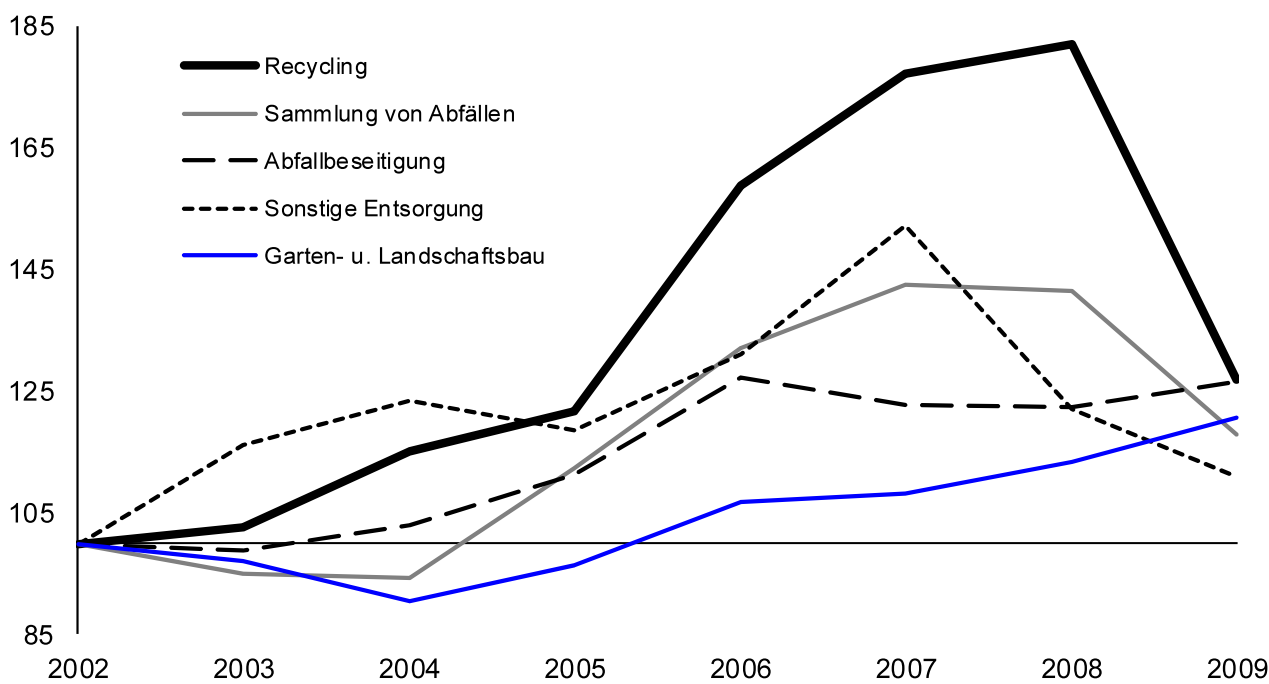

von der allgemeinen konjunkturellen Entwicklung abhängig. Sie profitierte in besonderem Maße von der positiven Preisentwicklung für Wertstoffe und Sekundärrohstoffe zwischen 2004 und 2008. So weist insbesondere die Preisentwicklung für Altmetalle Parallelen mit der Umsatzentwicklung in der Recyclingbranche auf: Nach einem geringen Anstieg 2003 legen die Preise zwischen 2004 und 2008 deutlich zu und brechen 2009 in Folge der Wirtschaftskrise und des damit verbundenen Produktionsrückgangs drastisch ein. Ein nicht unwesentlicher Grund für den Preisverfall auf dem Markt für Altmetalle und Schrott dürfte zudem die Einführung der „Abwrackprämie“ gewesen sein, die 2009 zu einem erheblich höheren Aufkommen an Altautos und somit an Schrott führte (Berninger und Kohlmeyer 2009).

Zweitens profitierte die Recyclingsparte von der zunehmenden Verlagerung von der Abfallbeseitigung hin zur Abfallverwertung, die durch das $\mathrm{KrW} / \mathrm{AbfG}$ angestoßen worden ist. So ist der Anteil des Abfallaufkommens, der verwertet wird, von $66 \%$ im Jahr 2005 auf $79 \%$ im Jahr 2009 gestiegen. ${ }^{8}$ Besonders stark nahm die Verwertungsquote 2006 in Folge der Novellierung des KrW/AbfG im Jahr $2005 \mathrm{zu}$, nach der eine Deponierung von Abfall nur nach Vorbehandlung erlaubt ist. In diesem Zusammenhang ist auch die rückläufige Entwicklung der Umsätze in der Sparte Abfallbeseitigung nach 2006 zu sehen. Die positive Umsatzentwicklung in der Abfallwirtschaft insgesamt dürfte auch auf die gute konjunkturelle Lage ab 2006/2007 zurückzuführen sein, die das Abfallaufkommen ansteigen ließ. Insbesondere die Abfälle aus Produktion und Gewerbe haben 2006 und 2007 deutlich zugenommen. Ein Anstieg ist

\footnotetext{
${ }^{8} \mathrm{Zu}$ den Beseitigungsverfahren zählen in der Abfallbilanz des Statistischen Bundesamtes die Ablagerung/Deponie, die thermische Beseitigung/Verbrennung und die Behandlung zur Beseitigung. Verwertungsverfahren sind die thermische/energetische Verwertung sowie die Behandlung und stoffliche Verwertung (Recycling).
}

auch bei den Bau- und Abbruchabfällen aufgrund der sich nach 2005 aufhellenden Baukonjunktur zu verzeichnen. Das Abfallaufkommen insgesamt nimmt 2006 und 2007 moderat zu, stagniert 2008 infolge der beginnenden Wirtschaftskrise und geht 2009 merklich zurück, was in Einklang mit der Umsatzentwicklung in der Abfallwirtschaft steht.

Betrachtet man die Entwicklung der sozialversicherungspflichtig Beschäftigten in der Abfallwirtschaft, so zeigt sich zwischen 2008 und 2010 ein moderater Anstieg von 153.941 auf 156.077. In den Sparten Abfallbeseitigung und Rückgewinnung bleibt die Beschäftigung in diesem Zeitraum praktisch unverändert. Die Wirtschaftskrise und die anschlieBende Erholung hinterlassen hier nur geringe Spuren in der Beschäftigungsentwicklung. Die weniger konjunkturabhängigen Entsorgungssparten Abfallsammlung und sonstige Entsorgung verzeichnen dagegen einen merklichen Beschäftigungsanstieg. Dies trifft ebenfalls auf den Gartenund Landschaftsbau zu (Abb. 3).

\subsection{Wettbewerbssituation und Strukturmerkmale}

Die Wettbewerbssituation in der Abfallwirtschaft und im Galabau wird anhand der Marktkonzentration analysiert. Als Indikator hierfür dient die Unternehmensdichte, also die Relation zwischen Unternehmensanzahl und Gesamtumsatz einer Branche. Je geringer die Unternehmensdichte, umso mehr Umsatz entfällt im Durchschnitt auf jedes Unternehmen und umso höher ist die Marktkonzentration.

In der Abfallwirtschaft ist die Unternehmensdichte zwischen 2002 und 2009 gesunken, d.h. die Marktkonzentration hat zugenommen. Hier machen sich die Unternehmenszusammenschlüsse im Entsorgungsgewerbe bemerkbar, die dazu führten, dass sich die Zahl der Unternehmen weit unterproportional zu den bis 2008 stark steigenden Umsätzen entwickelte. Im Galabau steigt die Unternehmensdichte bis 2004, entwickelt sich danach aber weitgehend paral- 
Abb. 3

Beschäftigungsentwicklung Abfallsparten und Galabau $(2008=100)$, Deutschland. Quelle: Statistik der sozialversicherungspflichtig Beschäftigten

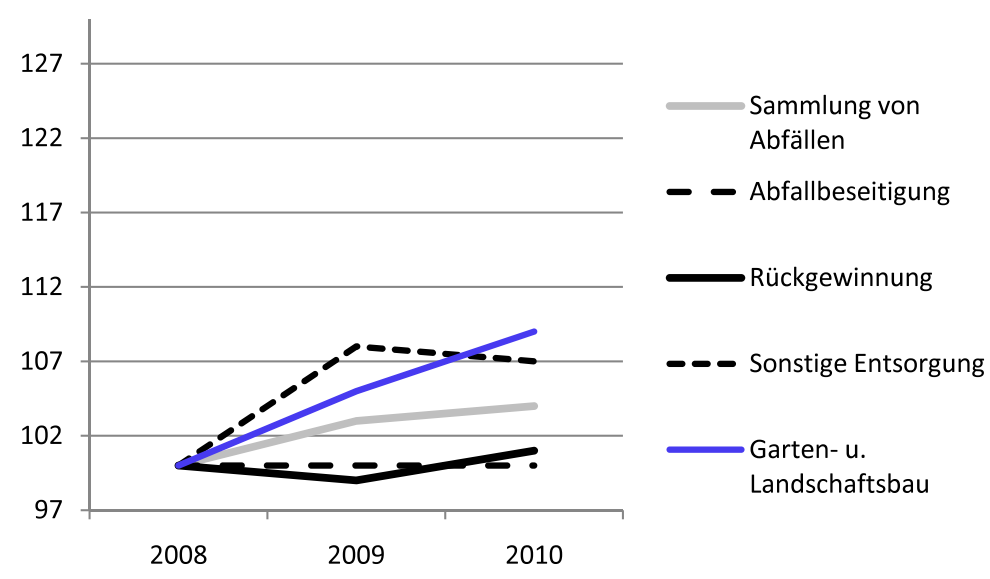

Abb. 4 Entwicklung der Unternehmensdichte (Anzahl USt-pflichtige Unternehmen in Relation zum Gesamtumsatz, $2002=100$ ), Abfallwirtschaft und Galabau, Deutschland. Quelle: Umsatzsteuerstatistik, eigene Berechnungen. Anmerkung: Branchenabgrenzung der Abfallwirtschaft 2009 nicht exakt identisch mit den Vorjahren

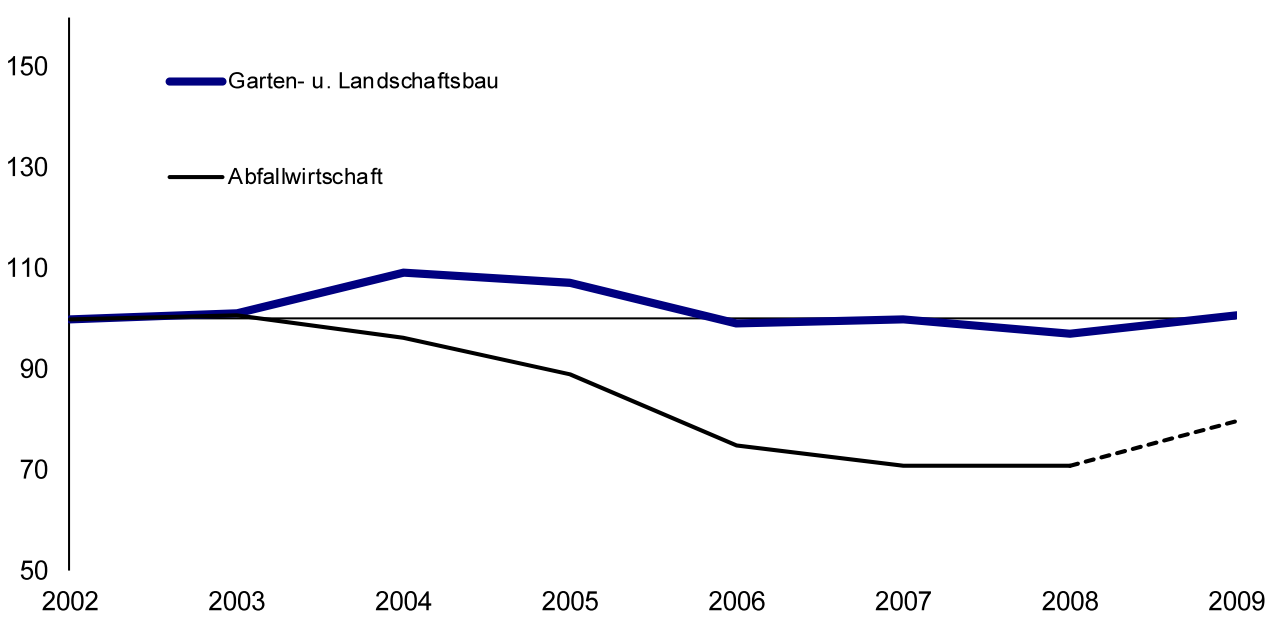

lel zur Unternehmensdichte in der Abfallwirtschaft. In beiden Branchen steigt die Unternehmensdichte im Krisenjahr 2009 wieder an (Abb. 4). Die Ursachen dafür sind in der Abfallwirtschaft jedoch andere als im Galabau. In der Abfallwirtschaft geht der Umsatz 2009 prozentual stärker zurück als die Unternehmensanzahl. Im Galabau steigt die Unternehmensanzahl stärker als der Umsatz. Das Ergebnis ist in beiden Fällen eine abnehmende Marktkonzentration.

Eine abnehmende Unternehmensdichte ist in allen Sparten der Abfallwirtschaft mit Ausnahme der sonstigen Entsorgung zu beobachten. Am stärksten ist dieser Trend bis 2008 in den Sparten Recycling und Abfallsammlung ausgeprägt. In der Abfallbeseitigung hingegen fällt der Rückgang der Unternehmensdichte bis 2008 am geringsten aus. 2009 kommt es im Recycling dann aufgrund des starken Umsatzeinbruchs zu einem deutlichen Anstieg der Unternehmensdichte (Abb. 5).

Wie ein Vergleich der absoluten Unternehmensdichte zeigt, ist die Unternehmensdichte im Galabau 2009 elfmal höher als in der Abfallwirtschaft. Demzufolge ist die Marktkonzentration in der Abfallwirtschaft deutlich größer. Weitere Strukturinformationen zu den beiden Branchen finden sich in den Kennzahlen zur Entlohnung, zur Produktivität und zur Kostenstruktur (Tab. 2). Die Arbeitsproduktivität gemessen am Umsatz je Beschäftigten ist in der Abfallwirtschaft um ein Vielfaches höher als im Galabau. Auch die Entgelte je Arbeitnehmer/in liegen in der Abfallwirtschaft deutlich höher. Innerhalb der Abfallwirtschaft ist die Produktivität (auch gemessen an der Bruttowertschöpfung je Beschäftigten $)^{9}$ in der Abfallbeseitigung und in der Recyclingbranche am höchsten. In diesen beiden Sparten ist die Produktion aufgrund des umfangreichen Einsatzes technischer Anlagen (Sortier-, Müllverbrennungs-, Recyclinganlagen) deutlich kapitalintensiver als in der Abfallsammlung und der sonstigen Entsorgung. Dies zeigt sich auch an dem geringeren Personalkostenanteil in der Abfallbeseitigung und beim Recycling. Insgesamt weist die Abfallwirtschaft einen höheren Materialkostenanteil und einen geringeren Personalkostenanteil auf als der Galabau, der durch ei-

\footnotetext{
${ }^{9}$ Die Bruttowertschöpfung je Beschäftigten ist - soweit verfügbar - ein besserer Indikator für die Produktivität als der Umsatz je Beschäftigten. Der Umsatz enthält auch den Materialaufwand, der in der Recyclingwirtschaft aufgrund des Einsatzes recyclingfähigen Materials als Produktionsinput sehr groß ist, wodurch auch der Umsatz je Beschäftigten dort außergewöhnlich hoch ist.
} 
Abb. 5 Entwicklung der Unternehmensdichte (Anzahl USt-pflichtige Unternehmen in Relation zum Gesamtumsatz, 2002=100), Abfallsparten und Galabau, Deutschland. Quelle: Umsatzsteuerstatistik, eigene Berechnungen. Anmerkung: Branchenabgrenzung der Abfallsparten 2009 nicht exakt identisch mit den Vorjahren

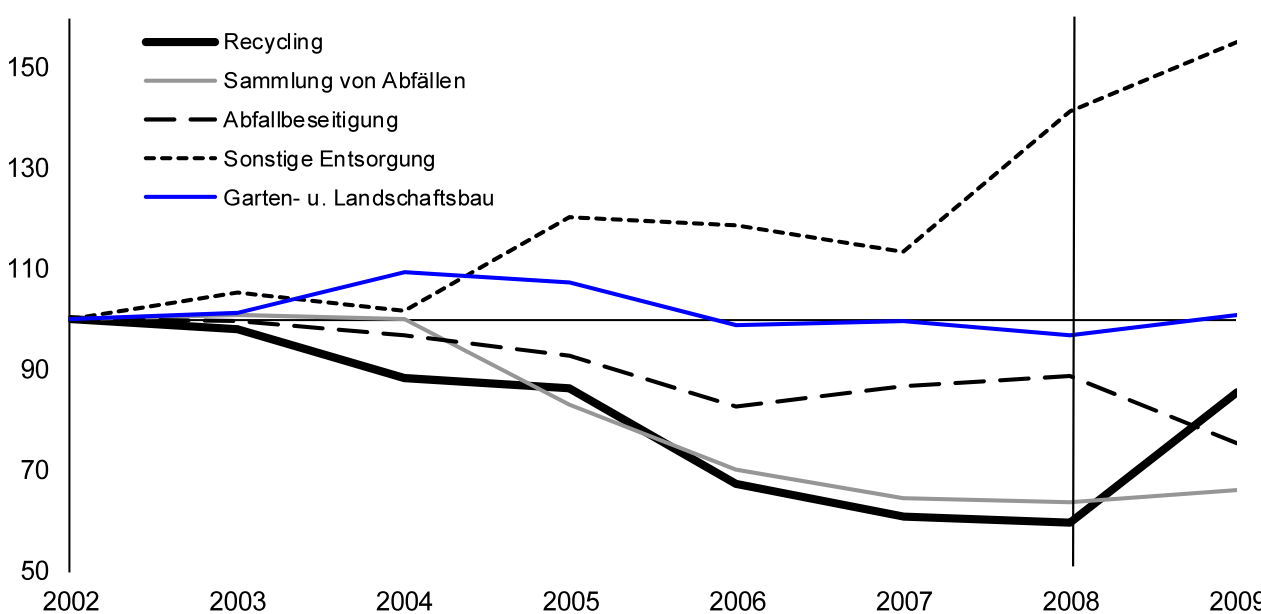

Tab. 2 Kennzahlen aus den Strukturerhebungen im Produzierenden Gewerbe und im Dienstleistungsbereich 2008

\begin{tabular}{|c|c|c|c|c|c|}
\hline & Abfallsammlung & Abfallbeseitigung & Rückgewinnung & Sonstige Entsorgung & Galabau $^{\mathrm{a}}$ \\
\hline Entgelt je Arbeitnehmer (EUR) & 29.860 & 34.134 & 29.534 & 29.817 & 17.500 \\
\hline BWS je Beschäftigten (Tsd. EUR) & 65 & 102 & 98 & 65 & k.A. \\
\hline Umsatz je Beschäftigten (Tsd. EUR) & 166 & 243 & 448 & 155 & 58 \\
\hline \multicolumn{6}{|l|}{ Anteil am Umsatz(\%) } \\
\hline Materialaufwand & 60,7 & 58,2 & 78,4 & 58,3 & 44,8 \\
\hline Personalkosten & 22,3 & 17,5 & 8,0 & 23,4 & 30,0 \\
\hline Investitionen & 6,8 & 8,3 & 3,0 & 3,4 & 7,0 \\
\hline
\end{tabular}

Anmerkungen: in der Abfallwirtschaft nur Unternehmen unter 1 Mill. EUR Jahresumsatz;

ainkl. Erbringung gärtnerischer Dienstleistungen; BWS = Bruttowertschöpfung, Materialaufwand (bezogene Waren, Dienstleistungen, Roh-, Hilfs- und Betriebsstoffe sowie sonstige betriebl. Aufwendungen inkl. Kosten für Leiharbeitnehmer/innen), Personalkosten (Entgelte + Sozialabgaben)

Quelle: Strukturerhebungen im Produzierenden Gewerbe und im Dienstleistungsbereich 2008, Kostenstrukturerhebung in sonstigen Dienstleistungsbereichen 2006, eigene Berechnungen

ne geringe Kapital- und eine hohe Arbeitsintensität gekennzeichnet ist.

Fasst man die Ergebnisse des Branchenbildes zusammen, so zeigt sich, dass die einzelnen Sparten der Abfallwirtschaft vor der Mindestlohneinführung durch eine unterschiedliche Entwicklung gekennzeichnet sind. Für die Kausalanalyse auf Basis des Kontrollgruppenansatzes bedeutet dies, dass ein Vergleich von Treatment- und Kontrollunternehmen nach Möglichkeit innerhalb der gleichen Sparte der Abfallwirtschaft vorgenommen werden sollte. Im Vergleich zum Galabau deuten die Resultate des Branchenbildes ebenfalls auf eine beträchtliche Divergenz der Trends sämtlicher betrachteten Größen hin. Da jedoch die Beschränkung auf den Kontrollgruppenansatz innerhalb der Branche das Risiko mit sich gebracht hätte, möglicherweise keine geeigneten Kontroll- und Treatmentunternehmen innerhalb derselben Sparte identifizieren zu können, sollte in der Kausalanalyse möglichst auch der Ansatz unter Verwendung einer weiteren Kontrollbranche zum Einsatz kommen. Vor dem
Hintergrund, dass der Galabau sich nicht als geeignete Kontrollbranche für die gesamte Branche der Abfallwirtschaft erweist, wurde der Kontrollbranchenansatz auf die Abfallbeseitigung eingeschränkt, für die die Unterschiede in der Entwicklung der Umsätze und Unternehmensdichte im Vergleich zum Galabau in der Tendenz am geringsten ausgefallen sind.

\section{Betroffenheit der Unternehmen vom Mindestlohn}

Die Analyse der Betroffenheit der Unternehmen vom Mindestlohn erfolgte auf Basis der Ergebnisse der CATI-Befragung, da im Rahmen der amtlichen Statistik zu Projektbeginn keine Daten für den aktuellen Rand vor der Mindestlohneinführung im Jahr 2010 zur Verfügung standen. Als „,betroffen“ werden solche Unternehmen bezeichnet, die vor der Mindestlohneinführung Beschäftigte unterhalb des Mindestlohnes entlohnt haben. In der Unternehmensbefragung 
Tab. 3 Regionale Betroffenheit vom Mindestlohn Abfall

\begin{tabular}{|c|c|c|c|}
\hline \multicolumn{2}{|l|}{ West } & \multicolumn{2}{|l|}{ Ost } \\
\hline Mittelwert (Std. Abw.) & Beob. (Ges.) & Mittelwert (Std Abw.) & Beob. (Ges.) \\
\hline
\end{tabular}

\section{Betroffenheit vom Mindestlohn}

Anteil der Unternehmen mit mind. 1 Mitarbeiter mit Std.-Lohn unter $8 € /$ ML (retrosp.)

Mitarbeiteranteil mit einem Stundenlohn unter $8 € / \mathrm{ML}$ in betroffenen Firmen (retrosp.)

Mind. 1 Mitarbeiter erhält derzeit den gesetzlichen Mindestlohn

Anteil der Mitarbeiter mit Mindestlohn in betroffenen Unternehmen

Erhöhung der Lohnkosten aufgrund des gesetzlichen Mindestlohns

Tarifverträge (im Retrospektivjahr)

Branchentarifvertrag

Haustarifvertrag

Kein Tarifvertrag

Orientierung an einem Branchentarif (wenn kein Tarifvertrag)

Beschäftigungsneutraler Mindestlohn

Maximaler Mindestlohn ohne Personalabbau ${ }^{\mathrm{a}}$

\begin{tabular}{|c|c|c|c|}
\hline $15,1 \%$ & 287 & $41,5 \%$ & 179 \\
\hline$(0,36)$ & & $(0,49)$ & \\
\hline $34,5 \%$ & 52 & $47 \%$ & 71 \\
\hline$(34,86)$ & & $(40,75)$ & \\
\hline $43,2 \%^{* * *}$ & 293 & $69,6 \%$ & 187 \\
\hline$(0,5)$ & & $(0,46)$ & \\
\hline $80,4 \%$ & 132 & $81,9 \%$ & 123 \\
\hline$(0,32)$ & & $(0,3)$ & \\
\hline $12 \%^{* * *}$ & 293 & $36,3 \%$ & 191 \\
\hline$(0,33)$ & & $(0,48)$ & \\
\hline $16,9 \%$ & 72 & $16,3 \%$ & 40 \\
\hline$(0,38)$ & & $(0,37)$ & \\
\hline $17,7 \%$ & 53 & $14,3 \%$ & 31 \\
\hline$(0,38)$ & & $(0,35)$ & \\
\hline $65,5 \%$ & 165 (290) & $69,3 \%$ & 115 (186) \\
\hline$(0,48)$ & & $(0,46)$ & \\
\hline $26 \%$ & 165 & $26,4 \%$ & 114 \\
\hline$(0,44)$ & & $(0,44)$ & \\
\hline $12,24 €^{* * *}$ & 218 & $10,64 € €$ & 139 \\
\hline$(3,47)$ & & $(2,73)$ & \\
\hline
\end{tabular}

Quelle: Unternehmensbefragung 2011. Unternehmensgewichtete Werte

${ }^{*},{ }^{* *},{ }^{* * *}$ bezeichnet einen statistisch signifikanten Unterschied der geschätzten Mittelwerte zwischen den Gruppen zum $10 \%$-, $5 \%$ - bzw. $1 \%$ Signifikanzniveau

${ }^{a}$ Hierbei lautete die Frage „Wenn der gesetzlichen Mindestlohn weiter steigen würde, ab welchem Mindestlohn müsste in Ihrem Unternehmen wahrscheinlich Personal abgebaut werden?“

2011 wurde daher die Information erhoben, wie hoch im jeweiligen Retrospektivjahr ${ }^{10}$ der Anteil der Arbeitskräfte mit einem Stundenlohn unter $8 €$ ausfiel. Dieses Lohnniveau entspricht in etwa dem Mindestlohn zum Zeitpunkt der Einführung Anfang 2010. Für die gesamte Branche belief sich der Anteil der betroffenen Unternehmen hochgerechnet auf ca. $23 \%$. Die mit den Beschäftigtenzahlen gewichteten Werte zeigen indes, dass der Anteil der Beschäftigten, die vor der Mindestlohneinführung unterhalb des Mindestlohnes entlohnt wurden, nur bei ca. $6 \%$ lag.

Tabelle 3 verdeutlicht, dass die Mindestlohnbetroffenheit in Ostdeutschland wesentlich ausgeprägter ist als in West-

\footnotetext{
${ }^{10}$ Das Retrospektivjahr war für den Großteil der Unternehmen das Jahr 2007, nur für diejenigen Unternehmen, die erst 2007 oder später gegründet wurden, wurde das Retrospektivjahr auf das dem Gründungsjahr folgende Jahr festgesetzt. Dies betrifft 30 der 492 befragten Unternehmen der Abfallwirtschaft.
}

deutschland. Während nur $15 \%$ der westdeutschen Unternehmen vom Mindestlohn betroffen sind, beläuft sich der entsprechende Anteil in Ostdeutschland auf $42 \%$. Für die Untergruppe der betroffenen Unternehmen lag der Anteil der Beschäftigten, die im Retrospektivjahr unterhalb des Mindestlohnes entlohnt wurden, im Mittel bei $35 \%$ bzw. $43 \%$, wobei diese Anteile sich jedoch in beiden Regionen nicht signifikant voneinander unterscheiden. Signifikante Unterschiede lassen sich jedoch für die derzeitige Mindestlohnbindung, d.h. den Anteil der Unternehmen, die genau nach Mindestlohn entlohnen (43\% in West- und $70 \%$ in Ostdeutschland) ${ }^{11}$ sowie für die Anteile der Unternehmen, die in Folge des Mindestlohnes mit einer Lohnkostenerhöhung konfrontiert waren (12\% in West- und $36 \%$ in Ostdeutschland), nachweisen. $\mathrm{Zu}$ beachten ist hier, dass die

\footnotetext{
${ }^{11}$ Dies betrifft $27 \%$ der Beschäftigten in Westdeutschland und $47 \%$ in Ostdeutschland.
} 
Werte in beiden Regionen von den Anteilen der Unternehmen, die vorher unterhalb des Mindestlohnes entlohnt haben, nach unten abweichen. Als mögliche Gründe für eine Abweichung sind vor allem eine mögliche Nicht-Einhaltung der Mindestlohnregulierung (Non-Compliance) sowie Reaktionen auf den Mindestlohn, wie z. B. eine Erhöhung der Arbeitsproduktivität zu nennen. Ebenso ist denkbar, dass der Mindestlohn als Orientierungsmarke zu einer Verschiebung der Lohnstruktur nach unten und daher zu keiner gesamten Lohnkostenerhöhung geführt hat (vgl. hierzu Abschn. 6.2).

Für das Ausmaß der Tarifbindung vor der Mindestlohneinführung finden sich keine statistisch signifikanten Unterschiede zwischen Ost- und Westdeutschland. Dies steht im Gegensatz zur in der Literatur häufig dokumentierten niedrigeren Tarifbindung ostdeutscher Unternehmen in der Gesamtwirtschaft (z. B. Ellguth und Kohaut 2011). Ohne zusätzliche repräsentative Daten über das Ausmaß der Tarifbindung in der Abfallwirtschaft lässt sich die Ost-West Differenz an dieser Stelle jedoch nicht validieren - z. B. könnte eine mögliche Ursache für den geringen Unterschied ebenfalls eine höhere Antwortbereitschaft tarifgebundener ostdeutscher Unternehmen sein. Zusammen mit dem höheren Ausmaß an Betroffenheit vom Mindestlohn ostdeutscher Unternehmen deuten die Ergebnisse darauf hin, dass der Anteil der westdeutschen befragten Unternehmen, die trotz fehlender Tarifbindung keine Entlohnung unterhalb des Mindestlohnes vorgenommen haben höher ist als in Ostdeutschland.

Wie bereits in Abschn. 2.1 dargelegt, ist für den Kontrollgruppenansatz von entscheidender Bedeutung, in welchem Ausmaß innerhalb der gleichen Sparte der Abfallwirtschaft betroffene und nicht betroffene Unternehmen identifiziert werden können. Der Grund hierfür liegt darin, dass die Annahme paralleler Trends für die verschiedenen Sparten häufig nicht erfüllt ist (vgl. Abschn. 3). Untersucht man die Betroffenheit getrennt nach Sparten, zeigt sich jedoch, dass sich keine Konzentration der Betroffenheit auf bestimmte Teilbereiche der Branche nachweisen lässt. So geben jeweils rund 11, 17 und $18 \%$ der Unternehmen in den Sparten Abfallsammlung, -beseitigung und Rückgewinnung in Westdeutschland an, vor der Mindestlohneinführung Beschäftigte unterhalb des Mindestlohnes entlohnt zu haben. Die Unterschiede sind jedoch nicht statistisch signifikant. Gleiches gilt für das Ausmaß der Betroffenheit in Ostdeutschland, wo jeweils rund 43, 37 und $44 \%$ der Unternehmen in den Sparten Abfallsammlung, -beseitigung und Rückgewinnung vor der Mindestlohneinführung unterhalb des Mindestlohnes entlohnt haben. Ebenso wenig ergeben sich signifikante Unterschiede nach Sparten im Hinblick auf die Anteile der Beschäftigten, die derzeit genau nach Mindestlohn entlohnt werden, sowie hinsichtlich der Anteile der Unternehmen, deren Lohnkosten nach eigenen Angaben durch den Mindestlohn erhöht wurden. In Westdeutschland variiert lediglich das Ausmaß der Betroffenheit gemessen am Anteil der betroffenen Beschäftigten signifikant über die Sparten und fällt in der Rückgewinnung mit $51 \%$ am größten aus.

Betrachtet man die Unterschiede ausgewählter beobachtbarer Indikatoren betroffener und nicht-betroffener Unternehmen, zeigt sich, dass der Anteil der privatwirtschaftlich organisierten Unternehmen unter den betroffenen Unternehmen in West- und Ostdeutschland signifikant höher ist als in den nicht betroffenen Unternehmen. Weiterhin lassen sich für Ostdeutschland insbesondere Unterschiede im Hinblick auf den beschäftigungsneutralen Mindestlohn sowie den Anteil geringfügig Beschäftigter und in Westdeutschland ebenfalls im Hinblick auf den beschäftigungsneutralen Mindestlohn sowie den Anteil der Fachkräfte feststellen. Überraschenderweise zeigen sich hinsichtlich der Tarifbindung keine signifikanten Unterschiede zwischen betroffenen und nicht betroffenen Unternehmen - der Anteil nicht-tarifgebundener Unternehmen unter den nichtbetroffenen ist nur geringfügig höher als unter den betroffenen Unternehmen. Dieses Ergebnis gilt sowohl für kommunale als auch private Unternehmen und ist insofern überraschend, als die untersten Tariflöhne privater Unternehmen über dem Niveau des Mindestlohnes lagen. Eine mögliche Ursache könnte im Einsatz von Leiharbeitskräften liegen, die vor der Mindestlohneinführung niedrigere Löhne als den Mindestlohn erhalten haben.

Zur Untersuchung der Lohnstruktur nach der Mindestlohneinführung wurde in der Unternehmensbefragung die Information erhoben, wie hoch im Jahr 2010 im Mittel der Anteil der Arbeitskräfte mit einem Stundenlohn in den Kategorien jeweils unter $8 €$, zwischen 8 und $9 €$ sowie zwischen 9 und $10 €$ ausfiel. Den Befragungsergebnissen zufolge ist der Anteil der Unternehmen mit Stundenlöhnen unterhalb von $8 €$ von im Mittel $23 \%$ vor der Mindestlohneinführung auf ca. $9 \%$ nach der Mindestlohneinführung gesunken. Die mit den Beschäftigtenzahlen gewichteten Werte zeigen, dass der Anteil der Beschäftigten, die in einem unter $8 €$ entlohnenden Unternehmen arbeiten, von ca. $21 \%$ auf $9 \%$ gesunken ist. Die Werte unterscheiden sich somit nur geringfügig von den unternehmensgewichteten Werten, da das Ausmaß der Betroffenheit über die unterschiedlichen Größenklassen keine signifikanten Unterschiede aufweist. Die Deskriptionen zeigen zudem, dass von den $9 \%$ der Beschäftigten, die nach der Einführung des Mindestlohnes in einem immer noch gering entlohnenden Unternehmen arbeiteten, $25 \%$ unterhalb von $8 €$ entlohnt wurden. Dies bedeutet, dass der Anteil der unterhalb von $8 €$ entlohnten Beschäftigten von vorher $6 \%$ auf 2,25\% nach der Mindestlohneinführung gesunken ist.

\section{Hypothesen}

Nachdem in den vorangegangenen Abschnitten die Entwicklung der Abfallwirtschaft bis kurz vor der Einführung 
des Mindestlohnes sowie das Ausmaß der Betroffenheit vom Mindestlohn dargelegt werden, sollen im folgenden Abschnitt Hypothesen hinsichtlich der Wirkungen auf die Beschäftigung und den Arbeitnehmerschutz diskutiert werden.

Beschäftigung Ist der Arbeitsmarkt ein Wettbewerbsmarkt und werden die Arbeitskräfte gemäß ihrer Produktivität entlohnt, senkt ein Mindestlohn die Beschäftigung, sofern er über dem gleichgewichtigen markträumenden Lohnsatz liegt (vgl. Borjas 2010). Fundamental anders sind die Beschäftigungseffekte von Mindestlöhnen zu bewerten, wenn am Arbeitsmarkt kein vollkommener Wettbewerb herrscht, sondern die Unternehmen Marktmacht gegenüber den Arbeitskräften ausüben (Monopson). In einem solchen Fall kann das Unternehmen den Marktlohn durch seine Arbeitsnachfrage selbst beeinflussen. Im Ergebnis liegen sowohl der Lohn als auch die Beschäftigung unterhalb des Wettbewerbsniveaus. Unternehmen fragen zu wenig Arbeit nach, um den Lohn noch unterhalb der Produktivität der Arbeitskräfte festsetzen zu können. Auf einem solchen Markt kann ein Mindestlohn u.U. zu positiven Beschäftigungseffekten führen, da der Mechanismus, dass eine geringere Arbeitsnachfrage zu einem geringeren Lohn führt, außer Kraft gesetzt wird (Manning 2003). Da in der Abfallwirtschaft eine niedrige Entlohnung unterhalb von $8 €$ von geringer Relevanz war, erscheinen etwaige monopsonistische Marktstrukturen vor der Mindestlohneinführung jedoch als wenig wahrscheinlich.

Geht man im Folgenden daher von einem wettbewerblichen Arbeitsmarkt aus, so beeinflussen die folgenden Faktoren das Ausmaß des negativen Beschäftigungseffekts:

- Substitutionsmöglichkeiten mit anderen Produktionsfaktoren

- die Intensität des Wettbewerbs bei den produzierten Gütern

- der Anteil der Arbeitskosten an den Gesamtkosten

Grundsätzlich gilt, dass negative Beschäftigungseffekte eines Mindestlohns umso geringer ausfallen sollten, je schwieriger es ist, die betroffene Beschäftigtengruppe durch andere Produktionsfaktoren, wie z. B. andere Beschäftigtengruppen oder Kapital, zu ersetzen. Neben diesem „Substitutionseffekt" sind weitere negative Effekte auf die Beschäftigung zu erwarten, die sich aus einer insgesamt geringeren Produktion ergeben (,Skaleneffekte“). Der Skaleneffekt fällt umso geringer aus, je weniger Konkurrenz auf dem relevanten Gütermarkt herrscht und je niedriger die Preiselastizität der Nachfrage ist. Der Grund hierfür ist, dass bei geringerem Wettbewerb die Unternehmen Lohnsteigerungen leichter über Preissteigerungen an die Abnehmer/innen überwälzen können und bei niedriger Preiselastizität der Nachfrage Preiserhöhungen die Nachfragemengen nur wenig ändern. Der Anteil der Arbeitskosten an den Gesamtkosten bestimmt schließlich das Ausmaß einer etwaigen Preissteigerung als Reaktion auf die Lohnsteigerung. Je höher dieser Anteil ist, desto stärker wird die mit der Lohnsteigerung einhergehende Güterpreissteigerung - und damit der negative Beschäftigungseffekt - ausfallen (vgl. hierzu z. B. Cahuc und Zylberberg 2004). Des Weiteren ist für die Höhe der Beschäftigungseffekte von Bedeutung, wie hoch der festgesetzte Mindestlohn oberhalb des vor der Mindestlohneinführung vorherrschenden Marktlohnes liegt.

Vor diesem Hintergrund ist zu erwarten, dass selbst für die vom Mindestlohn betroffenen Unternehmen in einigen Segmenten der Abfallwirtschaft mögliche negative Beschäftigungseffekte erheblich abgemildert werden bzw. unter Umständen gar nicht vorhanden sein könnten. Ursächlich hierfür sollten vor allem geringe Skaleneffekte insbesondere im Bereich der Hausmüllentsorgung sein. Die Kosten der Hausmüllentsorgung werden auf Basis des Gebührenrechts auf die Haushalte umgelegt, die wiederum aufgrund der im KrW-/AbfG geregelten Überlassungspflicht keine Ausweichmöglichkeiten bei Gebührenerhöhungen haben. Das im Gebührenrecht verankerte Kostendeckungsprinzip ermöglicht unmittelbar die Weitergabe erhöhter Lohnkosten über höhere Gebühren an die Endverbraucher/innen. Dies gilt nicht nur für die Hausmüllentsorgung durch kommunale Eigenbetriebe, sondern in der Regel auch bei Vergabe der Entsorgungsleistung an private Auftragnehmer, da aufgrund des Kostendeckungsprinzips ebenfalls erhöhte Fremdleistungskosten in die Gebührenbemessung einfließen können. Zudem erfolgt die Gebührenbemessung häufig auf Basis so genannter Preisgleitklauseln, die eine Weiterverrechnung von Kostenanstiegen erlauben. Die Beantwortung der Frage, inwiefern die Möglichkeit dieser durch das Kostendeckungsprinzip sowie von Preisgleitklauseln bestimmten Preisbildung tatsächlich zu geringeren Beschäftigungsreaktionen in den betroffenen Unternehmen führt, hängt nicht zuletzt auch vom politischen Druck auf die Kommunen $\mathrm{ab}$, die Gebühren niedrig zu halten und bedarf damit letztendlich der empirischen Klärung. Als weiteres Argument für geringe zu erwartende Beschäftigungseffekte ist anzuführen, dass die stark regulierten Bereiche der Hausmüllund der Verpackungsmüllentsorgung durch eine weitgehend konstante Nachfrage (Umfang der anfallenden Abfallmengen und Rhythmus der Sammlung und Abfuhr des Abfalls) und sehr geringe Möglichkeiten für einen arbeitssparenden technischen Fortschritt geprägt sind. Aus diesem Grunde ist ebenfalls wahrscheinlich, dass - sofern für einen Teil der vom Mindestlohn betroffenen Unternehmen negative Beschäftigungseffekte resultieren - dies bei weitgehender Konstanz der Nachfrage zu Verschiebungen der Produktion innerhalb der Branche führen sollte.

Arbeitnehmerschutz Aus sozialpolitischer Perspektive wird eine Mindestlohneinführung häufig damit begründet, Ar- 
beitnehmer/innen vor unzumutbaren Einkommens- oder Arbeitsbedingungen zu schützen. Eine zentrale pekuniäre GröBe ist die realisierte Einkommensverbesserung. Bei den vom Mindestlohn direkt betroffenen Beschäftigten sollte diese exakt der Differenz zwischen dem vor der Mindestlohneinführung gezahlten Lohn und dem Mindestlohn entsprechen. Für die pekuniäre Dimension des Arbeitnehmerschutzes ist somit der Anteil der Beschäftigten relevant, deren Entlohnung vorher unterhalb des Mindestlohnes gelegen hat. Die Ausführungen im vorherigen Abschnitt haben gezeigt, dass nur ein vergleichsweise geringer Anteil der Beschäftigten in der Abfallwirtschaft unterhalb des Mindestlohnes entlohnt wurde. Im Gegensatz hierzu sollte der Mindestlohn die Entlohnung von Leiharbeitskräften jedoch erheblich verbessert haben.

Selbst für den Fall, dass ein Teil der Beschäftigten vor der Mindestlohneinführung einen niedrigeren Lohn als den Mindestlohn erhalten hat, setzt eine Verbesserung der Einkommenssituation die "Compliance“ der betroffenen Arbeitgeber voraus. Hier ist etwa denkbar, dass mögliche Vermeidungsstrategien eine Falschdeklaration von Arbeitsstunden, die (nicht-zulässige) Einbeziehung von Zulagen in den Bruttostundenlohn sowie unbezahlte Überstunden beinhalten können. Da infolge der universellen Gültigkeit des Mindestlohnes in der Abfallwirtschaft wenige Möglichkeiten der Substitution durch andere Arbeitskräfte existieren, ist denkbar, dass stattdessen eine Verschiebung zu Beschäftigungsverhältnissen stattfindet, die die oben skizzierten Vermeidungsstrategien erleichtern.

Weiterhin sind zumindest in einem wettbewerblichen Arbeitsmarkt die Effekte auf die Zielgröße insgesamt uneindeutig, da ein oberhalb des Marktlohnes liegender Mindestlohn nur diejenigen Arbeitnehmer/innen besser stellt, die weiterhin beschäftigt bleiben. Mögliche Entlassungen als Reaktion könnten aber die durchschnittliche Einkommensposition verschlechtern. Die Hypothesen zur Zielgröße Beschäftigung (siehe oben) deuten jedoch darauf hin, dass möglicherweise in einigen Bereichen der Abfallwirtschaft geringe Beschäftigungseffekte zu erwarten sind, so dass etwaige Verbesserungen der Entlohnungssituation nicht notwendigerweise mit höheren Arbeitslosigkeitsrisiken bezahlt werden müssen.

Neben den Entlohnungseffekten für direkt vom Mindestlohn betroffene Beschäftigte sind auch Effekte auf die Entlohnung von Arbeitskräften möglich, deren Entlohnung oberhalb des Mindestlohnes liegt. So ist beispielsweise denkbar, dass Lohnkostensteigerungen am unteren Rand der Lohnverteilung durch Lohnsenkungen am oberen Rand kompensiert werden. Der Mindestlohn könnte in diesem Fall zu einer Art Orientierungsmarke für die Entlohnung in der Branche werden und somit zu einer verschlechterten Ein- kommenssituation eines Teils der Beschäftigten beitragen. ${ }^{12}$ Ebenso ist möglich, dass sich die Entlohnung derjenigen Beschäftigten verbessert, die vor der Mindestlohneinführung bereits oberhalb des Mindestlohnes entlohnt wurden. Eine potenzielle Erklärung hierfür ist, dass die Tarifparteien bzw. Unternehmen infolge von Fairness-Überlegungen den Anreiz haben, die vor der Mindestlohneinführung bestehende Lohnstruktur zu erhalten.

Vom Mindestlohn ausgelöste Änderungen beim zu zahlenden Lohn können sich auch auf die nicht pekuniären Merkmale der Arbeitsplätze auswirken. Einerseits könnten sich die Arbeitsbedingungen verbessern, falls die Lohnsteigerung eine Produktivitätssteigerung auslöst und produktivere Arbeitsplätze neben einem höheren Lohn auch bessere Rahmenbedingungen für die Arbeitnehmerinnen und Arbeitnehmer bieten. Andererseits könnten sich die Arbeitsbedingungen verschlechtern, falls Unternehmen, um die durch den Mindestlohn bedingten Kostensteigerungen aufzufangen, sich bei der Arbeitsplatzqualität bietende Spielräume ausschöpfen. Denkbar ist insbesondere, dass die Arbeitsbelastungen steigen, weil Arbeit verdichtet wird oder mehr unbezahlte Überstunden geleistet werden müssen, dass freiwillige Arbeitgeberleistungen zurückgenommen werden oder dass verstärkt ungeschützte Beschäftigungsformen - befristete Arbeitsverhältnisse, geringfügige Beschäftigung, Leiharbeit - zum Einsatz kommen, die wegen des geringeren Arbeitnehmerschutzes einen systematischen Kostenvorteil aufweisen.

\section{Wirkungsanalyse}

\subsection{Wirkungen des Mindestlohnes auf die Zielgröße Beschäftigung}

Um die Beschäftigung zu messen, wurde in der Befragung die durchschnittliche Anzahl der Beschäftigten im Jahre 2010 erhoben. Hier sollten ebenfalls Auszubildende, befristet Beschäftigte und geringfügig Beschäftigte mit einbezogen werden. Nicht erfasst wurden Zeitarbeitskräfte, mithelfende Familienangehörige sowie die Eigentümer/innen des Unternehmens. Darüber hinaus wurde erfragt, inwiefern sich die Beschäftigung gemessen an der Anzahl der Personen gegenüber dem Retrospektivjahr verändert hat. Hierzu

\footnotetext{
${ }^{12}$ Die in Tab. 12 dokumentierte Lohnstruktur für tarifgebundene Unternehmen vor und nach der Mindestlohneinführung verdeutlicht allerdings, dass ein Absenken der Löhne für tarifgebundene Unternehmen wenig wahrscheinlich ist. Der Grund hierfür ist, dass die dort festgelegten untersten Vergütungsgruppen entweder ohnehin deutlich oberhalb des Mindestlohnes liegen oder wie im TVöD-E über die Entwicklungsstufen an eine bestimmte Betriebszugehörigkeit gebunden sind. Ebenso sind positive Spillover-Effekte für tarifgebundene Unternehmen wenig wahrscheinlich, da der Mindestlohn die Lohnstruktur für diese nicht geändert hat.
} 
Tab. 4 Varianten der Treatment-Messungen

Treatment $_{1}(\mathrm{~A} 1)$

Treatment $_{2}(\mathrm{~A} 2)$

Treatment $_{3}(\mathrm{~A} 2)$

(Treatment-Intensität)
$\mathrm{D}_{\text {Abfallbeseitigung }}=1$, wenn Sektorzugehörigkeit $=$ Abfallbeseitigung und wenn Anteil der

vor 2010 unterhalb von $8 €$ entlohnten Beschäftigten $>0$ ist

$=0$ für Kontrollgruppe Garten- und Landschaftsbau

$=1$, Abfallwirtschaft und wenn Anteil der vor 2010 unterhalb von $8 €$ entlohnten

Beschäftigten $>0$ ist

$=0$, für Kontrollgruppe Abfallwirtschaft und Anteil $=0$

$=$ Anteil der vor 2010 unterhalb von $8 €$ entlohnten Beschäftigten, wenn

Anteil $>0+$ Abfallwirtschaft

$=0$ für Kontrollgruppe Abfallwirtschaft Anteil $=0$ wurden drei Antwortkategorien (Anzahl der Beschäftigten hat zugenommen, ist gleichgeblieben, hat abgenommen) zugelassen. Für die Unternehmen, die eine Abnahme oder $\mathrm{Zu}-$ nahme angegeben haben, wurde schließlich die Differenz der Beschäftigten im Vergleich zum Retrospektivjahr erhoben. Die so ermittelte Differenz wurde in der Wirkungsanalyse als Hauptergebnisvariable für die Entwicklung der Beschäftigung zwischen dem Retrospektivjahr vor der Mindestlohneinführung und dem Jahr 2010 nach der Mindestlohneinführung herangezogen.

Um die Wirkung der Mindestlohneinführung zu quantifizieren, wurden unterschiedliche Spezifikationen geschätzt, die sich im Wesentlichen durch die Messung des Treatments (d.h. der Betroffenheit vom Mindestlohn) sowie durch die Festlegung der Kontrollgruppe unterscheiden. Die unterschiedlichen Varianten der Messung des Treatments sind in Tab. 4 zusammengefasst. Die erste Variante der TreatmentMessung definiert die Betroffenheit für die Verwendung des Kontrollgruppenansatzes A1, in dem Unternehmen des Galabaus als Kontrollgruppe verwendet werden. Basierend auf den Überlegungen des Branchenbildes wird dieser Ansatz nur für den Bereich der Abfallbeseitigung verwendet.

Die zweite Variante der Treatment-Messung definiert die Betroffenheit innerhalb der gesamten Branche der Abfallwirtschaft für den Kontrollgruppenansatz A2. Treatment 2 nimmt für alle Unternehmen der Abfallwirtschaft den Wert Eins an, wenn mindestens ein/e Beschäftigte/r vor der Mindestlohneinführung einen Lohn unterhalb von $8 €$ erhalten hat. Als letzte Variante wird die Betroffenheit durch die so genannte Treatment-Intensität gemessen, d.h. durch den Anteil der von der Mindestlohneinführung betroffen Beschäftigten auf Unternehmensebene.

Bei der Verwendung der unterschiedlichen Treatmentvariablen wurde folgende Gleichung geschätzt:

$y_{i, t}-y_{i, t-1}=b_{0}+b_{1} \cdot$ Treatment $_{1,2,3}+b_{2} \cdot x_{i, t}+u_{i, t}$

Hierbei bezeichnet $y$ die Ergebnisvariable (im folgenden Abschnitt die Anzahl der Beschäftigten bzw. der natürliche Logarithmus der Anzahl der Beschäftigten) in Unternehmen $i, t$ ist der Zeitpunkt nach der Mindestlohneinführung (hier: 2010) und $t-1$ das jeweilige Retrospektivjahr. $u_{i t}$ ist eine Zufallsvariable, die zufällige Störeinflüsse auffängt. Fügt man den Spezifikationen zusätzlich noch Kontrollvariablen für die Region (Ost-West), Größenklassen und die Rechtsform (Kommunal/Privat) in dem Vektor $x_{i, t}$ mit dem zugehörigen Parametervektor $b_{2}$ hinzu, so bedeutet dies, dass der Parameter $b_{1}$ auf Basis des Vergleiches von betroffenen und nicht betroffenen Unternehmen innerhalb der so spezifizierten Gruppen ermittelt wird. Grundsätzlich gilt, dass $b_{1}$ den Effekt des Treatments auf die Veränderung der Ergebnisvariablen misst. Bei der Verwendung des Treatment 3 , welches in dem Intervall von 0 und 1 liegen kann, ist zu beachten, dass der Parameter $b_{1}$ für die Ausprägung Treatment ${ }_{3}=1$ zu interpretieren ist. Hier misst $b_{1}$ den Effekt der Mindestlohneinführung für Unternehmen, die vorher zu $100 \%$ Beschäftigte unterhalb von $8 €$ entlohnt haben (d.h. mit Treatment $_{3}=1$ ). Für Unternehmen, für die der Anteil geringer als $100 \%$ ist, reduziert sich der Effekt somit entsprechend.

\subsubsection{Beschreibung der Beschäftigungsentwicklung}

In Tab. 5 wird zunächst die Beschäftigungsentwicklung für die Abfallwirtschaft sowie den Galabau dargestellt. Bei der Abfallwirtschaft wird zusätzlich zwischen den unterschiedlichen Sparten sowie zwischen betroffenen und nicht betroffenen Unternehmen (im Sinne der Messung durch Treatment 2 ) unterschieden.

Die Beschäftigungsentwicklung wird durch $\ln \left(y_{i, t}\right)-$ $\ln \left(y_{i, t-1}\right)$ gemessen, was dem Wachstum der Anzahl der Beschäftigten in Unternehmen $i$ entspricht. Um das Beschäftigungswachstum auf Branchenebene dazustellen, sind die folgenden Deskriptionen mit der Beschäftigtenzahl gewichtet. Die Werte zeigen, dass das Beschäftigungswachstum der befragten Unternehmen der Abfallwirtschaft in der Stichprobe hochgerechnet $6,6 \%$ beträgt, während der entsprechende Wert für den Galabau bei 4,4 \% liegt. Die differenzierte Betrachtung des Beschäftigungswachstums nach Sparten innerhalb der Abfallwirtschaft zeigt, dass die Sparte Rückgewinnung mit 10,8 \% das höchste Beschäftigungswachstum aufweist, wohingegen die Sparte Abfallbeseitigung lediglich eine Wachstumsrate von $4,4 \%$ verzeichnet. 
Tab. 5 Deskription des Beschäftigungswachstums

\begin{tabular}{|c|c|c|c|c|}
\hline & \multirow{2}{*}{$\frac{\text { Ost }}{\text { Mittelwert (Std.-Abw.) }}$} & \multirow{2}{*}{$\frac{\text { West }}{\text { Mittelwert (Std.-Abw.) }}$} & \multirow{2}{*}{$\frac{\text { Gesamt }}{\text { Mittelwert (Std.-Abw.) }}$} & \multirow[t]{2}{*}{ Beob } \\
\hline & & & & \\
\hline \multicolumn{5}{|l|}{ (Unter-)Sektor } \\
\hline \multirow[t]{2}{*}{ Abfallsammlung } & $1,4 \%$ & $8,2 \%$ & $6,7 \%$ & 135 \\
\hline & $(0,34)$ & $(0,16)$ & $(0,21)$ & \\
\hline \multirow[t]{2}{*}{ Abfallbeseitigung } & $3,4 \%$ & $4,6 \%$ & $4,4 \%$ & 188 \\
\hline & $(0,2)$ & $(0,29)$ & $(0,28)$ & \\
\hline \multirow[t]{2}{*}{ Abfallrückgewinnung } & $2,5 \%$ & $11,9 \%$ & $10,8 \%$ & 137 \\
\hline & $(0,4)$ & $(0,25)$ & $(0,27)$ & \\
\hline \multirow[t]{2}{*}{ Galabau } & $2,5 \%$ & $4,9 \%$ & $4,4 \%$ & 253 \\
\hline & $(0,31)$ & $(0,44)$ & $(0,41)$ & \\
\hline \multicolumn{5}{|l|}{ Abfallwirtschaft } \\
\hline \multirow[t]{2}{*}{ Gesamt } & $1,4 \%$ & $7,5 \%$ & $6,5 \%$ & 450 \\
\hline & $(0,30)$ & $(0,25)$ & $(0,26)$ & \\
\hline \multirow[t]{2}{*}{ Nicht betroffen } & $1,3 \%$ & $6,8 \%$ & $6,1 \%$ & 320 \\
\hline & $(0,33)$ & $(0,2)$ & $(0,22)$ & \\
\hline \multirow[t]{2}{*}{ Betroffen } & $1,7 \%$ & $10,7 \%$ & $8,1 \%$ & 120 \\
\hline & $(0,24)$ & $(0,41)$ & $(0,37)$ & \\
\hline
\end{tabular}

Quelle: Unternehmensbefragung 2011. Beschäftigungsgewichtete Werte

Die nach Ost- und Westdeutschland differenzierten Werte belaufen sich auf 8,2\%, 4,6\% und 11,9\% für die Abfallsammlung, -beseitigung und Rückgewinnung für Westdeutschland, wohingegen die entsprechenden Raten für Ostdeutschland 1,4 \%, 3,4 \% und 2,5\% betragen. Im Hinblick auf den Ost/West-Unterschied entspricht dies dem grundsätzlichen Muster, das sich auf Grundlage der amtlichen Statistik ergibt. Bezogen auf die Rangfolge der Sparten weist die Abfallbeseitigung in Westdeutschland in den amtlichen Daten ebenfalls das niedrigste Beschäftigungswachstum auf. Allerdings sind die Wachstumsraten auf Grundlage der amtlichen Daten durchgängig wesentlich geringer (vgl. auch Abb. 3). ${ }^{13}$ Dies deutet einerseits darauf hin, dass die erhobene Stichprobe tendenziell verstärkt wachsende Unternehmen abbildet. Eine weitere Erklärung für die Divergenz zwischen dem Beschäftigungswachstum der befragten Unternehmen und dem der amtlichen Statistik könnte zudem im Messfehler der erhobenen Beschäftigungsinformation liegen.

Vergleicht man schließlich das Beschäftigungswachstum betroffener und nicht-betroffener Unternehmen der Abfallwirtschaft, so zeigt sich, dass betroffene Unternehmen eher ein höheres Beschäftigungswachstum als nicht-betroffene Unternehmen aufweisen - der Unterschied ist allerdings

\footnotetext{
${ }^{13}$ So ist gemäß der Statistik für die sozialversicherungspflichtig Beschäftigten der BA die Beschäftigung in der Abfallwirtschaft zwischen 2007 und 2010 lediglich von 155.267 auf 156.077 Beschäftigte gestiegen.
}

nicht statistisch signifikant. Bevor im nächsten Abschnitt die Ergebnisse der kausalen Wirkungsanalyse vorgestellt werden, wird vorweg die direkte Einschätzung der befragten Unternehmen hinsichtlich möglicher negativer Beschäftigungseffekte auf die Mindestlohneinführung dargestellt. So wurden in der Unternehmensbefragung 2011 diejenigen Unternehmen, die angegeben haben, infolge der Mindestlohneinführung mit einer Lohnkostenerhöhung konfrontiert worden zu sein, direkt nach möglichen Reaktionen auf eine durch den Mindestlohn induzierte Kostenerhöhung gefragt. Dies betrifft 111 der 492 befragten Unternehmen, was hochgerechnet ca. $19 \%$ der Unternehmen in der Abfallwirtschaft entspricht. Hiervon haben nur ca. $14.7 \%$ auf die Frage, inwiefern die Strategie eines Personalabbaus als Reaktion auf den Mindestlohn in Frage kommt, mit „Trifft voll und ganz zu“ oder mit „Trifft eher zu“ geantwortet. Dies entspricht mit hochgerechnet $3 \%$ somit einem vergleichsweise geringem Anteil der Gesamtbranche.

\subsubsection{Regressionsergebnisse Beschäftigung}

Tabelle 6 (im Anhang A) weist zunächst die Regressionsergebnisse auf Basis der Verwendung von Treatment ${ }_{1}$ aus. Die in der Zeile „Treatment ${ }_{1}$ “ ausgewiesenen Schätzergebnisse zeigen, dass der geschätzte Wert für $b_{1}$ über die unterschiedlichen Spezifikationen zwischen 0 und -0.019 liegt. Die Spezifikationen deuten zudem darauf hin, dass der geschätzte Koeffizient unter Berücksichtigung der Region und der Größenklassen kleiner wird, was letztlich reflektiert, dass 
Unternehmen der Abfallbeseitigung im Vergleich zum Galabau weniger häufig im Osten vertreten sind sowie durch größere Unternehmen geprägt sind. ${ }^{14}$ Der geschätzte Koeffizient ist jedoch, was die Größenordnung anbelangt, klein (zwischen 1 und 2 Prozentpunkten) und ist in keiner der Spezifikationen signifikant. Zudem ist zu berücksichtigten, dass der Galabau gemäß den amtlichen Daten bereits vor der Mindestlohneinführung ein höheres Beschäftigungswachstum aufgewiesen hat, so dass selbst bei einem signifikant negativen Effekt nach der Bereinigung unterschiedlicher Trends der in diesem Ausmaß geschätzte negative Beschäftigungseffekt verschwinden würde. Die letzte Spalte von Tab. 6 (sowie der folgenden Tabellen) weist die Ergebnisse einer Spezifikation aus, die statt des Beschäftigungswachstums als abhängige Variable eine Indikatorvariable für die Reduzierung der Beschäftigung enthält. Der Koeffizient für „Treatment 1 “ zeigt, dass entsprechend den obigen Ergebnissen der geschätzte Effekt auf eine negative Beschäftigungsentwicklung positiv ist, allerdings nicht signifikant von Null verschieden. ${ }^{15}$ Die Ergebnisse aus Tab. 6 bleiben ebenfalls von der Größenordnung her erhalten, wenn man die betroffenen Unternehmen nur auf die privatwirtschaftlichen Unternehmen einschränkt (hier nicht ausgewiesen).

Tabelle 7 (im Anhang A) weist die Schätzergebnisse unter Verwendung des Treatment 2 aus. Hier zeigt sich, dass unter Verwendung unterschiedlicher Kontrollvariablen der Schätzer für $b_{1}$ positiv ist, jedoch in keiner der Spezifikationen signifikant von Null verschieden. Ein ähnliches Muster erhält man, wenn man die Betroffenheit mit Hilfe der Treatment-Intensität (Treatment 3 ) misst (vgl. Tab. 8). Der geschätzte Koeffizient wird von der Tendenz her kleiner, bleibt jedoch nahe bei Null positiv und ist in keiner der Spezifikationen signifikant (Tab. 7). Beim Kontrollgruppenansatz innerhalb der Abfallwirtschaft ist zu beachten, dass die Ergebnisse grundsätzlich durch Spillover-Effekte innerhalb der Branche verzerrt sein können. So haben die Überlegungen in Abschn. 5 deutlich gemacht, dass negative Beschäftigungseffekte in der Treatmentgruppe bei unterstellter weitgehender Konstanz der Nachfrage über Verschiebungen der Produktion innerhalb der Branche ebenfalls zu Beschäftigungsveränderungen der Kontrollgruppe führen können. Die obigen Schätzergebnisse zeigen jedoch, dass solche Spillovereffekte von geringer Relevanz zu sein

\footnotetext{
${ }^{14}$ Dieses Ergebnis entspricht auch der Verteilung der Umsätze nach Größenklassen auf Basis der Umsatzsteuerstatistik (siehe Kapitel 6.2. im Evaluationsbericht Egeln et al. (2011)).

${ }^{15}$ Spillover-Effekte, die den Effekt weiterhin verzerren könnten, sind nach Angaben der befragten Unternehmen von geringer Relevanz. So habenr 228 der 260 befragten Unternehmens des Galabaus auf die Frage „Wie hat die Einführung des Mindestlohnes die Nachfrage nach den von Ihnen angeboten Dienstleistungen verändert?“ mit „Gar nicht" geantwortet (weiterhin zugelassen waren die Kategorien „Positiv“ und „Negativ“).
}

scheinen, da das Beschäftigungswachstum in den nicht betroffenen Unternehmen eher niedriger als in den betroffenen Unternehmen innerhalb der Branche ausfällt. Weitere mögliche Spillover-Effekte können daraus resultieren, dass sich infolge der Mindestlohneinführung das Lohnniveau auch oberhalb des Mindestlohnes und damit auch die Beschäftigung in nicht-betroffenen Unternehmen verändert hat. Inwiefern solche Effekte relevant sind, konnte jedoch in der Evaluation infolge der unzureichenden Datenlage zur Lohnverteilung nicht untersucht werden.

Zur Überprüfung der Robustheit wurden die Spezifikationen in Tab. 6 und Tab. 7 (im Anhang A) mit einer etwas restriktiveren Messung der Treatment-Variablen geschätzt. Hierbei wurde berücksichtigt, dass ein gewisser Anteil der betroffenen Unternehmen trotz Mindestlohneinführung immer noch unterhalb des Mindestlohnes entlohnt. Zur präziseren Definition der Betroffenheit wurden daher sämtliche Treatment-Definitionen nur auf die Gruppe derjenigen Unternehmen eingeschränkt, die nach der Mindestlohneinführung nicht mehr unterhalb von $8 €$ entlohnen (die so genannten „,betroffenen Complier“). Selbst die Verwendung dieser restriktiveren Definition der Betroffenheit ändert die in Tab. 6 und Tab. 7 (im Anhang A) ausgewiesenen Ergebnisse nicht, so dass das vorher nachgewiesene Muster der Resultate erhalten bleibt.

\subsubsection{Heterogene Beschäftigungseffekte}

Bei den vorangegangenen Analysen wurde bislang nicht berücksichtigt, dass sich ein potenzieller Beschäftigungseffekt der Mindestlohnwirkung über unterschiedliche Gruppen von Unternehmen unterscheiden kann. Die Analyse der Branchenentwicklung in Abschn. 3 hat gezeigt, dass die betrachteten Strukturindikatoren wie Beschäftigung und Umsätze sich in den unterschiedlichen Sparten der Branche unterschiedlich entwickelt haben. Während die unterschiedlichen Trends in der Beschäftigungsentwicklung durch die Aufnahme von Indikatoren für die unterschiedlichen Sparten und Größenklassen sowie Ost- und Westdeutschland im vorherigen Abschnitt zwar berücksichtigt wurden, lag den vorangegangenen Spezifikationen immer noch die Annahme eines homogenen Effektes $b_{1}$ zugrunde. Um zu überprüfen, ob sich der Koeffizient $b_{1}$ über verschiedene Gruppen unterscheidet, wurden die Treatment-Variablen mit Indikatorvariablen für unterschiedliche Merkmale der Unternehmen interagiert. In einer Spezifikation, die beispielsweise einen unterschiedlichen Treatment-Effekt für ost- und westdeutsche Unternehmen zulässt, wird die Betroffenheitsvariable zusätzlich mit dem entsprechenden Merkmal (hier der Indikator für Ostdeutschland) multipliziert und als erklärende Variable aufgenommen:

$$
\begin{aligned}
y_{i, t}-y_{i, t-1}= & b_{0}+b_{1} \cdot \text { Treatment }_{1,2,3} \\
& +b_{1 \_ \text {Ost }} \cdot \text { Treatment }_{1,2,3} \cdot \text { Ost } \\
& +b_{2} \cdot x_{i, t}+u_{i, t}
\end{aligned}
$$


Analog zur der obigen Spezifikation wurden jeweils heterogene Beschäftigungseffekte der Mindestlohneinführung für ost- und westdeutsche Unternehmen, die unterschiedlichen Größenklassen der Unternehmen sowie für die verschiedenen Sparten der Abfallwirtschaft ermittelt. Die Schätzergebnisse dieser Spezifikationen sollen im Folgenden nicht detailliert dargestellt werden, sondern werden der Kürze halber nur zusammengefasst. Insgesamt zeigen die interagierten Schätzungen, dass sich keine signifikanten Interaktionseffekte für Ostdeutschland für die unterschiedlichen Größenklassen nachweisen lassen. Lediglich bei Schätzung heterogener Effekte über die unterschiedlichen Sparten der Abfallwirtschaft deuten die Resultate vor allem für Treatment 2 auf einen negativen Beschäftigungseffekt in der Abfallsammlung hin, während die Effekte für die Abfallbeseitigung und die Rückgewinnung ein positives Vorzeichen aufweisen. Allerdings ist lediglich der differenzielle Effekt im Vergleich zur Abfallbeseitigung signifikant, der Beschäftigungseffekt für die Abfallsammlung gemessen durch $b_{1}$ selbst ist nicht signifikant von Null verschieden. Dies bedeutet, dass durch die Betroffenheit der Beschäftigungseffekt in der Abfallsammlung zwar geringer ausfällt als in der Abfallbeseitigung, der negative Gesamteffekt für die Abfallsammlung und der positive Gesamteffekt für die Abfallbeseitigung nicht von Null abgegrenzt werden können.

Welche inhaltlichen Erklärungsgründe lassen sich für mögliche unterschiedliche Beschäftigungseffekte der Mindestlohneinführung in der Abfallsammlung finden? Die Überlegungen in Abschn. 5 haben deutlich gemacht, dass das Ausmaß möglicher negativer Beschäftigungseffekte u.a. vom Anteil der Arbeitskosten an den Gesamtkosten abhängt. Im Hinblick auf die Bedeutung der Arbeitskosten hat das Branchenbild gezeigt, dass die Abfallsammlung tendenziell den höchsten Anteil der Personalkosten an den Gesamtkosten aufweist. Um zu überprüfen, inwiefern unterschiedliche Intensitäten der Bedeutung des Produktionsfaktors Arbeit für unterschiedliche Beschäftigungseffekte in den Sparten der Abfallwirtschaft verantwortlich sind, wurden ebenfalls heterogene Beschäftigungseffekte für Unternehmen mit hoher und niedriger Personalkostenbedeutung ermittelt. Hierzu wurden Unternehmen mit einem Personalkostenanteil von entweder mehr als $50 \%$ oder $30 \%$ der Kategorie „Hoher Personalkostenanteil“" zugeordnet. Die Ergebnisse zeigen, dass für Unternehmen mit einem Personalkostenanteil von mehr als $50 \%$ der Beschäftigungseffekt tatsächlich signifikant negativer ausfällt als für die Referenzgruppe. Der Gesamteffekt ist jedoch statistisch nicht signifikant. ${ }^{16}$

\footnotetext{
${ }^{16}$ Wie diese heterogenen Effekte zu bewerten sind, ist a-priori uneindeutig. Handelte es sich bei den personalkostenintensiven Unternehmen z. B. um unterdurchschnittlich produktive Unternehmen, so hätte die Mindestlohneinführung tendenziell eine Konzentration der Beschäftigung auf produktivere Unternehmen zur Folge. Ohne weitere detaillierte Informationen zur Produktivität der Unternehmen lassen sich hierzu jedoch keine Aussagen treffen.
}

Um die Rolle der Preisüberwälzung höher Lohnkosten für unterschiedlich hohe Beschäftigungseffekte zu untersuchen, wurden weiterhin heterogene Effekte je nach Art der Auftraggeber zugelassen. Die Treatment-Variablen wurden hierzu mit Indikator-Variablen interagiert, die anzeigen, ob ein Unternehmen überwiegend private Auftraggeber hat. Der erwartete differenzielle Effekt ist hier negativ, da private Auftraggeber im Gegensatz zu öffentlichen Auftraggebern höhere Lohnkosten weniger leicht in Form von Preissteigerungen an die Verbraucher/innen überwälzen können. Die Interaktionseffekte weisen in den Spezifikationen zwar erwartungsgemäß ein negatives Vorzeichen auf, werden aber wieder sehr ungenau geschätzt. ${ }^{17}$

Die tendenziell positiv geschätzten Koeffizienten der verwendeten Treatment-Variablen werfen die Frage auf, inwiefern die Ergebnisse auf ein mögliches Monopson in der Abfallwirtschaft hindeuten. Gemäß der Überlegungen in Abschn. 5 kann in einem Monopson eine Mindestlohneinführung die Marktmacht der Arbeitgeber einschränken und zu höherer Beschäftigung führen, wenn der Mindestlohn nicht zu hoch angesetzt wird. Um dies zu untersuchen, wurde eine Spezifikation geschätzt, in der die Treatment-Variablen mit einer Indikatorvariablen für mögliche Marktmacht der Arbeitgeber interagiert werden. Diese nimmt den Wert Eins an, wenn Unternehmen die Frage „Glauben Sie, dass geringer Qualifizierte in andere Unternehmen abwandern würden, wenn Ihr Unternehmen Ihnen geringere Löhne zahlen würde?" verneint haben. Die Ergebnisse zeigen jedoch, dass der Interaktionseffekt nicht das erwartete positive Vorzeichen aufweist und nicht signifikant von Null verschieden ist.

\subsection{Arbeitnehmerschutz}

Wie bereits in Abschn. 5 dargelegt, hat das Ziel des Arbeitnehmerschutzes sowohl eine pekuniäre als auch eine nicht pekuniäre Dimension. Während die pekuniären Aspekte der Mindestlohneinführung bereits Gegenstand von Abschn. 4 waren, sollen im Folgenden die nicht-pekuniären Dimensionen sowie die Wirkungen der Mindestlohneinführung für zunächst nicht direkt betroffene Beschäftigte beleuchtet werden.

Zur Überprüfung der in Abschn. 5 dargestellten Hypothesen wird der Effekt der Mindestlohneinführung wieder mit Hilfe der Schätzgleichung (1) ermittelt. Bei den Ergebnisvariablen werden vor allem Veränderungen in der Belegschaftsstruktur, Veränderungen des Krankenstandes und der Motivation sowie Veränderungen des Anteils bezahlter Überstunden als möglicher Form der Nichteinhaltung der Mindestlohnregelungen betrachtet. Da es sich bei den Ergebnisvariablen um Indikatorvariablen mit der Ausprägung

\footnotetext{
${ }^{17}$ Ähnlich ungenaue Ergebnisse erhält man, wenn man heterogene Effekte für private und öffentliche Unternehmen, für Unternehmen mit niedriger und hoher Arbeitsnachfrageelastizität zulässt.
} 
0 oder 1 handelt, wurden die Gleichungen durch Probitmodelle geschätzt. Der Kürze halber werden die Schätzergebnisse im Folgenden nicht ausgewiesen, sondern nur zusammengefasst. Insgesamt zeigen die geschätzten marginalen Effekte, dass die entsprechenden Treatment-Variablen nur für wenige Ergebnisgrößen signifikant sind. So hat die Mindestlohneinführung insbesondere unter Verwendung von Treatment ${ }_{2}$ und Treatment ${ }_{3}$ einen erhöhten Einsatz von ungelernten Arbeitskräften zur Folge. Konkret hat sich der Anteil der Ungelernten in den betroffenen Unternehmen im Vergleich zur Kontrollgruppe der nicht betroffenen Unternehmen innerhalb der Abfallwirtschaft um 10 Prozentpunkte erhöht. Weiterhin zeigen die Ergebnisse, dass eine Erhöhung des Anteils der zuvor unterhalb des Mindestlohnes Beschäftigten um 10 Prozentpunkte mit einer Erhöhung des Anteils von ungelernten Arbeitskräften um 2 Prozentpunkte einhergeht. Ebenso ergibt sich unter Treatment 3 ein signifikant positiver Effekt auf den Anteil geringfügiger Beschäftigung sowie auf die tatsächliche Arbeitszeit ungelernter Arbeitskräfte. Die restlichen Wirkungen auf die Ergebnisgrößen wie den Krankenstand, die Motivation sowie die Weiterbildung sind hingegen sämtlich unbestimmt.

Das Ergebnis, dass der Anteil an ungelernten Beschäftigten durch die Mindestlohneinführung zunimmt, wirft die Frage auf, inwiefern das zuvor beschriebene Szenario einer Senkung der Entlohnung von Relevanz ist. Dominiert der Effekt des Mindestlohnes als untere Orientierungsmarke, kehren sich die Hypothesen hinsichtlich der kausalen Effekte auf die Ergebnisgrößen gerade um. In diesem Fall wären somit eher ein negativer Effekt auf die Motivation und die Personalzugänge sowie ein erhöhter Krankenstand und vermehrte Personalabgänge zu erwarten, zudem sollte keine Zunahme ungeschützter Beschäftigungsverhältnisse sowie keine Verdichtung der Arbeitsleistung in Form einer erhöhten Arbeitszeit und einer geringeren Überstundenkompensation resultieren.

Dass der Mindestlohn möglicherweise als untere Orientierungsmarke dient, könnte Ursache dafür sein, dass der Anteil der betroffenen Unternehmen grundsätzlich den Anteil der mit einer Lohnkostenerhöhung konfrontierten Unternehmen übersteigt (Tab. 3). Von den 123 betroffenen Unternehmen in der Abfallwirtschaft (d.h. die Unternehmen, die vor der Mindestlohneinführung unterhalb von $8 €$ entlohnt haben) haben 44 Unternehmen (hochgerechnet $35 \%$ der betroffenen Unternehmen) angegeben, dass der Mindestlohn zu keiner Lohnkostenerhöhung geführt hat.

Inwieweit liefert diese Abweichung Evidenz dafür, dass der Mindestlohn für diese Unternehmen unter Umständen eine Absenkung der Entlohnung zur Folge gehabt hat? Zur Beantwortung dieser Frage wurden die oben diskutierten Probitregressionen jeweils getrennt für die betroffenen mit einer Lohnkostenerhöhung konfrontierten Unternehmen und für solche ohne Lohnkostenerhöhung ermittelt.
Bei der Interpretation der marginalen Effekte der TreatmentVariablen auf die Ergebnisgrößen für die betrachteten Untergruppen muss allerdings beachtet werden, dass die Effekte nicht notwendigerweise als kausale Effekte interpretiert werden können. Dies trifft besonders auf die Ergebnisvariablen zu, die die Lohnkosten direkt beeinflussen können (wie beispielsweise der Einsatz geringfügiger Beschäftigung sowie die Arbeitszeit und Überstundenkompensation) und somit die Selektion in die Untergruppen bestimmen.

Die Ergebnisse der Schätzungen, die getrennt für die betrachteten Untergruppen ermittelt wurden, finden sich in Tab. 9. Betrachtet man zunächst den Unterschied der Effekte auf den Anteil Ungelernter zwischen den beiden Gruppen, so liefern die Ergebnisse nur schwache Evidenz dafür, dass die Unternehmen, die angeben mit keiner Lohnkostenerhöhung konfrontiert gewesen zu sein, den Mindestlohn als untere Orientierungsmarke nutzen.

Zudem deuten die Ergebnisse daraufhin, dass gerade für die betroffenen Unternehmen, für die der Mindestlohn nicht mit einer Lohnkostenerhöhung verbunden ist, die Mindestlohneinführung mit einem verstärkten Einsatz geringfügiger Beschäftigung sowie mit einer Zunahme der tatsächlichen Arbeitszeit ungelernter Arbeitskräfte verbunden ist. Diese Ergebnisse sind allerdings nicht als kausal zu interpretieren, sondern deuten vielmehr darauf hin, dass gerade diese Maßnahmen dazu geführt haben können, dass der Mindestlohn die Lohnkosten insgesamt nicht erhöht hat. Zudem zeigen die Schätzergebnisse, dass sich für die betroffenen Unternehmen ohne Lohnkostenerhöhung in Folge des Mindestlohnes tendenziell die Motivation der Arbeitskräfte verringert sowie der Krankenstand erhöht hat. $\mathrm{Zu}$ beachten ist hier wiederum, dass die Effekte auf die Ergebnisgrößen tendenziell (betragsmäßig) unterschätzt sein sollten, da die betrachteten Ergebnisvariablen einen direkten Einfluss auf die Lohnkosten haben und somit die Einteilung der Unternehmen in die betrachteten Untergruppen direkt beeinflussen.

Wie oben dargelegt, könnte eine mögliche Ursache für die verringerte Motivation und den erhöhten Krankenstand darin liegen, dass ein Teil dieser Unternehmen den Mindestlohn als untere Orientierungsmarke nutzt, da in Folge der dadurch induzierten Lohnsenkung die Motivation sinken und der Krankenstand steigen sollte. Eine alternative Erklärung wäre, dass die verringerte Motivation und der erhöhte Krankenstand gerade das Resultat zunehmender Arbeitsverdichtungen sowie zunehmender irregulärer Beschäftigungsformen in diesen Unternehmen sind (siehe oben). Um diese zu überprüfen, wurden in den Spezifikationen mit den Ergebnisvariablen zum Krankenstand und zur Motivation die Indikatorvariablen zur Veränderung der Arbeitszeit und Vergütung der Überstunden als Erklärungsvariablen mit aufgenommen. Die Ergebnisse dieser erweiterten Spezifikationen (hier nicht ausgewiesen) zeigen in der Tat, dass die Veränderung der Motivation vollständig durch die veränderte Arbeitszeit- und Überstundenvergütung erklärt wird. 
Im Gegensatz dazu verändern sich für die Ergebnisvariable Krankenstand die geschätzten marginalen Effekte aus Tab. 9 (im Anhang A) nach Aufnahme dieser Kontrollvariablen nicht. Zusammengefasst liefern diese Ergebnisse insgesamt nur schwache Evidenz dafür, dass der Mindestlohn als untere Orientierungsmarke dient und für einen Teil der Beschäftigten zu schlechteren Entlohnungsbedingungen geführt hat.

\section{Schlussfolgerungen}

Ziel des folgenden Beitrages war es, die Ergebnisse der Evaluation der Auswirkungen des Mindestlohns in der Abfallwirtschaft, die am Zentrum für Europäische Wirtschaftsforschung (ZEW) in Zusammenarbeit mit dem Institut für angewandte Sozialwissenschaft (infas) durchgeführt wurde, zusammenfassend darzustellen.

Insgesamt deuten die Ergebnisse der Wirkungsanalyse auf Basis der eigens für die Evaluation durchgeführten Unternehmensbefragung darauf hin, dass bis auf wenige Ausnahmen sämtliche ermittelte Beschäftigungseffekte von der Größenordnung her nahe bei null liegen und nicht statistisch signifikant sind. Dies gilt auch, wenn man die Effekte getrennt für Ost- und Westdeutschland, für die verschiedenen Sparten der Branche sowie getrennt nach Unternehmensgrößenklassen untersucht. Lediglich für Unternehmen der Abfallsammlung sowie für Unternehmen mit einem Lohnkostenanteil von mehr als $50 \%$ sind differenzielle Beschäftigungseffekte nachweisbar. Diese Gruppen von Unternehmen weisen jeweils signifikant negativere Beschäftigungseffekte auf als Unternehmen der anderen Sparten der Branche bzw. weniger arbeitsintensive Unternehmen. Die Gesamtbeschäftigungseffekte werden jedoch auch für diese Untergruppen sehr unpräzise geschätzt und sind nicht von Null abgrenzbar. Bezogen auf den Arbeitnehmerschutz finden sich Hinweise darauf, dass die Mindestlohnerhöhung den Anteil geringfügiger Beschäftigung in den betroffenen Unternehmen signifikant erhöht sowie einen positiven Einfluss auf die Arbeitszeit ungelernter Arbeitskräfte gehabt hat.

Die Ergebnisse der Wirkungsanalyse sind jedoch insgesamt vor dem Hintergrund möglicher Messfehler zu interpretieren. Hiernach ist grundsätzlich nicht auszuschließen, dass die Ungenauigkeit der geschätzten Effekte zu einem gewissen Anteil auf die mangelnde Präzision der Messung der Zielgrößen durch die Unternehmensbefragung zurückgeht. Zudem zeigt der Vergleich mit Daten aus der amtlichen Statistik, dass das Beschäftigungswachstum der befragten Unternehmen vom Beschäftigungswachstum der Grundgesamtheit der Branche nach oben abweicht. Diese Abweichung kann einerseits durch den Messfehler in der Beschäftigung erklärt werden, ist aber andererseits auch auf mögliche Selektionseffekte z. B. aufgrund einer höheren Teilnahmebereitschaft wachsender Unternehmen zurückzuführen. A-priori gibt es aber keinen Hinweis darauf, dass gerade wachsende Unternehmen eine höhere Teilnahmebereitschaft aufweisen. So wäre ebenfalls denkbar, dass gerade vom Mindestlohn stark negativ betroffene Unternehmen eine überdurchschnittlich hohe Teilnahmebereitschaft aufweisen, um gegenüber wirtschaftspolitischen Entscheidungsträgern negative Konsequenzen kommunizieren zu können. Insgesamt hätten Selektionsprozesse im Gegensatz zum Messfehler in der Beschäftigung eine systematische Über- oder Unterschätzung des Effektes zur Folge ohne eine Validierung der Beschäftigungsinformation der befragten Unternehmen mit externen Datenquellen kann an dieser Stelle jedoch nicht abschließend beurteilt werden, welche der Konsequenzen dieser beiden Mechanismen hier dominieren.

Trotz der Datenproblematik fügt sich der zentrale Befund, dass die Einführung des Mindestlohnes keine spürbaren Effekte auf die Beschäftigung in der Branche gehabt hat, in das umfassendere Bild ein, das im Rahmen der Evaluation durch die Ergebnisse der Expertengespräche mit Branchenvertretern vervollständigt wurde. Zudem stützen die Ergebnisse die eingangs ausgearbeiteten Überlegungen im Hinblick auf die erwarteten Beschäftigungseffekte. Hiernach können die fehlenden Beschäftigungseffekte vor allem durch eine weitgehend konstante Nachfrage nach der Entsorgung von Abfällen zumindest im Bereich der Hausmüllentsorgung sowie durch die mangelnde Substituierbarkeit von Beschäftigten in der Branche erklärt werden. Letztere resultiert vor allem aus der universellen Gültigkeit des Mindestlohnes für sämtliche Beschäftigte der Branche sowie aus den geringen Substitutionsmöglichkeiten von Arbeit durch Kapital. Eine weitere Erklärung für die fehlenden Beschäftigungseffekte könnte darin liegen, dass der Lohnabstand zwischen den Niedriglöhnen der betroffenen Unternehmen und dem Mindestlohn gering ausfällt. Diese Dimension der Betroffenheit konnte jedoch auf Basis der derzeit verfügbaren Datenlage nicht erfasst werden.

Insgesamt hat der Beitrag deutlich gemacht, dass die Evaluation der Mindestlohneinführung in der Abfallwirtschaft durch zwei zentrale Herausforderungen gekennzeichnet war. Die erste Schwierigkeit betraf die kurze Geltungsdauer des Mindestlohnes seit der Einführung am 1.1.2010. Das zweite, eng damit verbundene Problem resultierte aus der Datenlage. Während die im Rahmen der Evaluation gewonnenen Ergebnisse erste wichtige Erkenntnisse hinsichtlich der Wirkungen des Mindestlohnes liefern, wäre es zweifellos von Vorteil, in möglichen Folgestudien die oben angesprochenen Probleme aufzugreifen. 


\section{Executive summary}

This article presents a summary of the evaluation of a sectorspecific minimum wage in the German waste management industry. The minimum-wage first became effective in January 2010 for all employers and employees in the waste management industry. The underlying minimum wage agreement, which had been negotiated between the sector's collective bargaining parties, set a standard of 8,02 $€$ per hour.

The study summarised in this article consists of two parts: first, a descriptive analysis of the sector's market conditions and, second, a causal evaluation of the minimum wage's impact on economic outcomes, such as employment and working conditions. The causal analysis is based on differencein-differences estimates using two different control groups: First, employers from a control sector that was not subject to a minimum wage and second, employers from the waste management industry itself who were not affected by the introduction of the minimum wage. The data used for the analyses stem from different sources, such as the German Federal Statistical Office, the Mannheim Enterprise Panel collected by ZEW, and finally a firm-level survey in the waste management and control sector which was conducted primarily for the purpose of the evaluation.

The empirical evidence from the survey data suggests that prior to the introduction of the minimum wage only 23 per cent of employers paid wages below eight euros, and this applied primarily to Eastern German and to private-sector firms. Overall, only 6 per cent of employees received wages below the minimum wage. The difference-in-difference estimates indicate that the minimum wage had no significant impact on employment within the first year after its introduction in January 2010. This result is consistent with the notion that imperfect competition in the underlying product market facilitates the pass-through of cost increases to the consumers via price increases. This is because municipal firms have a monopoly over household waste disposal. According to German legislation, the cost recovery principle pertaining to waste disposal fees allows for the direct transmission of higher labour costs in the form of higher fees to households, whose demand for waste removal services tends to remain relatively constant. In terms of working conditions, our results provide some first weak evidence of an increase in marginal employment relationships as well as effective working time.

\section{Kurzfassung}

Der vorliegende Beitrag liefert eine Zusammenfassung der Ergebnisse der Evaluation der Einführung des Mindestlohnes in der Abfallwirtschaft. Der Mindestlohn in der Abfallwirtschaft trat per Rechtsverordnung über die Aufnahme der
Abfallwirtschaft in das Arbeitnehmerentsendegesetz mit einem flächendeckenden Mindestlohn in Höhe von 8,02 Euro bundesweit erstmals zum 1. Januar 2010 in Kraft.

Die Evaluation setzt sich aus einem Branchenbild sowie einer kausalen Wirkungsanalyse des Mindestlohnes auf Basis einer Unternehmensbefragung im Hinblick auf die Zielgrößen Beschäftigung, Arbeitnehmerschutz und Wettbewerb zusammen. Die Kausalanalyse wurde auf Basis von Differenzen-in-Differenzen Schätzungen mit zwei verschiedenen Kontrollgruppen durchgeführt: (1) mit Unternehmen einer nicht vom Mindestlohn betroffenen Branche und (2) mit nicht betroffenen Unternehmen der Abfallwirtschaft, die vor der Mindestlohneinführung bereits oberhalb des Mindestlohnes entlohnt haben. Für die Analysen wurden Daten der amtlichen Statistik, das Mannheimer Unternehmenspanel (MUP) sowie Daten der für die Evaluation durchgeführten Unternehmensbefragung ausgewertet. Die Evidenz auf Basis der Befragungsdaten deutet darauf hin, dass die Betroffenheit der Branche vom Mindestlohn als gering einzustufen ist. Die Ergebnisse zeigen, dass hochgerechnet $23 \%$ der befragten Unternehmen der Abfallwirtschaft vor der Mindestlohneinführung Entgelte unterhalb des Mindestlohnes gezahlt haben. Auf Beschäftigtenebene waren jedoch nur rund $6 \%$ aller Beschäftigten der Branche betroffen. Hierbei haben vor allem ostdeutsche und privatwirtschaftliche Unternehmen Teile ihrer Beschäftigten unterhalb des Mindestlohnes entlohnt. Die Resultate der Wirkungsanalyse mit Hilfe verschiedener Kontrollgruppenansätze weisen darauf hin, dass die Einführung des Mindestlohnes innerhalb der bisherigen Geltungsdauer auf die Beschäftigung keine messbaren Effekte entfaltet hat. Diese Ergebnisse sind grundsätzlich mit der Überlegung vereinbar, dass infolge einer weitgehend konstanten Nachfrage nach der Entsorgung von Abfällen und der Möglichkeit der Überwälzung höherer Lohnkosten in höhere Preise geringe Beschäftigungseffekte einer Mindestlohneinführung zu erwarten sind. Dies betrifft insbesondere den Bereich der Hausmüllentsorgung, bei dem das im Gebührenrecht verankerte Kostendeckungsprinzip unmittelbar die Weitergabe erhöhter Lohnkosten über höhere Gebühren an die Endverbraucher und -verbraucherinnen ermöglicht, deren Nachfrage nach der Entsorgung von Abfällen relativ preisunelastisch ist. Bezogen auf den Arbeitnehmerschutz lässt sich als Folge des Mindestlohnes eine Tendenz zur Verdichtung der Arbeit sowie zur Zunahme ungeschützter Beschäftigungsverhältnisse feststellen.

Danksagung Wir danken Jürgen Egeln, Christian Rammer, Helmut Schröder und Holger Schütz für hilfreiche Diskussionen und Unterstützung bei den Analysen der Langfassung des Endberichtes. 


\section{Anhang A: Tabellenanhang}

Tab. 6 Abfallbeseitigung vs. Galabau

\begin{tabular}{|c|c|c|c|c|c|c|}
\hline \multirow{2}{*}{$\begin{array}{l}\text { Abhängige Variable } \\
\text { Erklärende Variable }\end{array}$} & \multicolumn{5}{|c|}{ Beschäftigungswachstum } & \multirow{2}{*}{$\begin{array}{l}\text { Indikator Besch. } \\
\text { gesunken }\end{array}$} \\
\hline & $\begin{array}{l}\text { Koeff. } \\
\text { (Std.-Fehler) }\end{array}$ & $\begin{array}{l}\text { Koeff. } \\
\text { (Std.-Fehler) }\end{array}$ & $\begin{array}{l}\text { Koeff. } \\
\text { (Std.-Fehler) }\end{array}$ & $\begin{array}{l}\text { Koeff. } \\
\text { (Std.-Fehler) }\end{array}$ & $\begin{array}{l}\text { Koeff. } \\
\text { (Std.-Fehler) }\end{array}$ & \\
\hline \multicolumn{7}{|l|}{ Treatment $_{1}$} \\
\hline Abfallbeseitigung & $\begin{array}{l}0 \\
(0,041)\end{array}$ & $\begin{array}{l}-0,001 \\
(0,042)\end{array}$ & $\begin{array}{l}-0,016 \\
(0,048)\end{array}$ & $\begin{array}{l}-0,019 \\
(0,052)\end{array}$ & $\begin{array}{l}-0,008 \\
(0,052)\end{array}$ & $\begin{array}{l}0,048 \\
(0,046)\end{array}$ \\
\hline \multicolumn{7}{|l|}{ Region } \\
\hline Ostdeutschland & & $\begin{array}{l}-0,02 \\
(0,039)\end{array}$ & $\begin{array}{l}-0,033 \\
(0,038)\end{array}$ & $\begin{array}{l}-0,039 \\
(0,036)\end{array}$ & $\begin{array}{l}-0,030 \\
(0,042)\end{array}$ & $\begin{array}{l}-0,004 \\
(0,039)\end{array}$ \\
\hline \multicolumn{7}{|l|}{ Unternehmensgröße } \\
\hline Mittelgroß (11-100 Beschäftigte) & & & $\begin{array}{l}0,088 \\
(0,055)\end{array}$ & $\begin{array}{l}0,086 \\
(0,056)\end{array}$ & $\begin{array}{l}0,105 \\
(0,064)\end{array}$ & $\begin{array}{l}-0,107^{* *} \\
(0,050)\end{array}$ \\
\hline Groß (>100 Beschäftigte) & & & $\begin{array}{l}0,032 \\
(0,068)\end{array}$ & $\begin{array}{l}0,006 \\
(0,074)\end{array}$ & $\begin{array}{l}0,021 \\
(0,081)\end{array}$ & $\begin{array}{l}0,007 \\
(0,094)\end{array}$ \\
\hline \multicolumn{7}{|c|}{ Entwicklung der Konkurrenz (Vergleich mit Retrospektivjahr) } \\
\hline Zunahme & & & & $\begin{array}{l}-0,057 \\
(0,057)\end{array}$ & $\begin{array}{l}-0,092 \\
(0,068)\end{array}$ & $\begin{array}{l}0,058 \\
(0,062)\end{array}$ \\
\hline Abnahme & & & & $\begin{array}{l}0,052 \\
(0,046)\end{array}$ & $\begin{array}{l}0,021 \\
(0,045)\end{array}$ & $\begin{array}{l}-0,103 \\
(0,080)\end{array}$ \\
\hline \multicolumn{7}{|l|}{ Entwicklung des Umsatzes } \\
\hline Veränderung zum Retrospektivjahr & & & & & $\begin{array}{l}0,175^{* * *} \\
(0,049)\end{array}$ & $\begin{array}{l}-0,080^{* *} \\
(0,032)\end{array}$ \\
\hline Konstante & $\begin{array}{l}0,044 \\
(0,035)\end{array}$ & $\begin{array}{l}0,048 \\
(0,041)\end{array}$ & $\begin{array}{l}0,016 \\
(0,057)\end{array}$ & $\begin{array}{l}0,042 \\
(0,060)\end{array}$ & $\begin{array}{l}0,029 \\
(0,065)\end{array}$ & $\begin{array}{l}0,195^{* * *} \\
(0,056)\end{array}$ \\
\hline Bestimmtheitsmaß & $-0,002$ & $-0,004$ & 0,002 & 0,006 & 0,124 & 0,077 \\
\hline Beobachtungen & 441 & 441 & 441 & 425 & 345 & 352 \\
\hline
\end{tabular}

Quelle: Unternehmensbefragung 2011. Beschäftigungsgewichtete Werte. Standardfehler der Koeffizienten sind in Klammern ${ }^{*},{ }^{* *},{ }^{* * *}$ gibt jeweils die statistische Signifikanz zum $10 \%-, 5 \%$ - bzw. $1 \%$-Signifikanzniveau an 


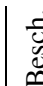

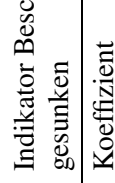

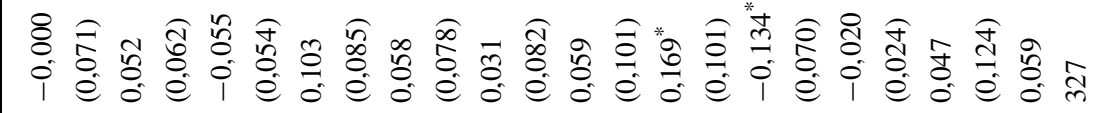

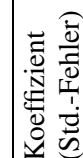

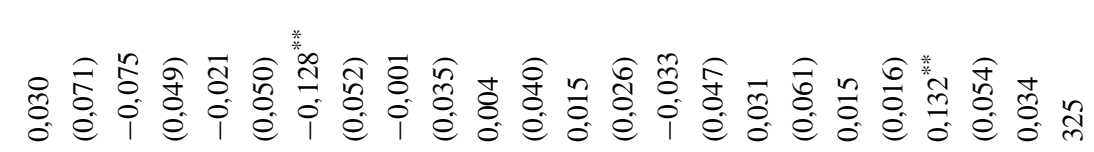

离 $8^{2}$

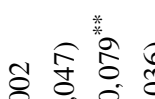

ô.

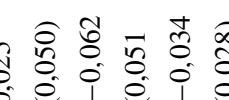

ชิ สิ

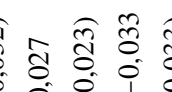

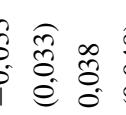

\section{$\stackrel{\infty}{0}$}

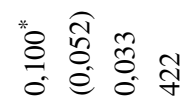

离

急

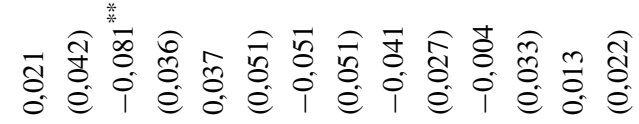

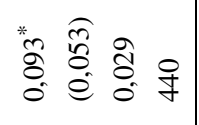

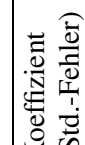
(1)

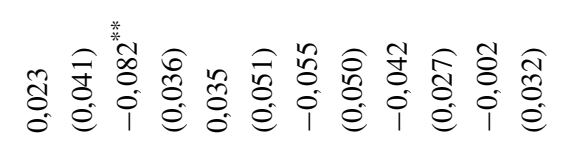

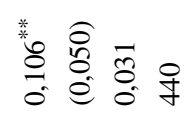

를

量

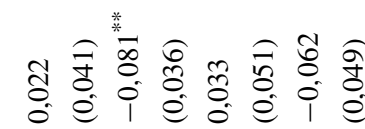

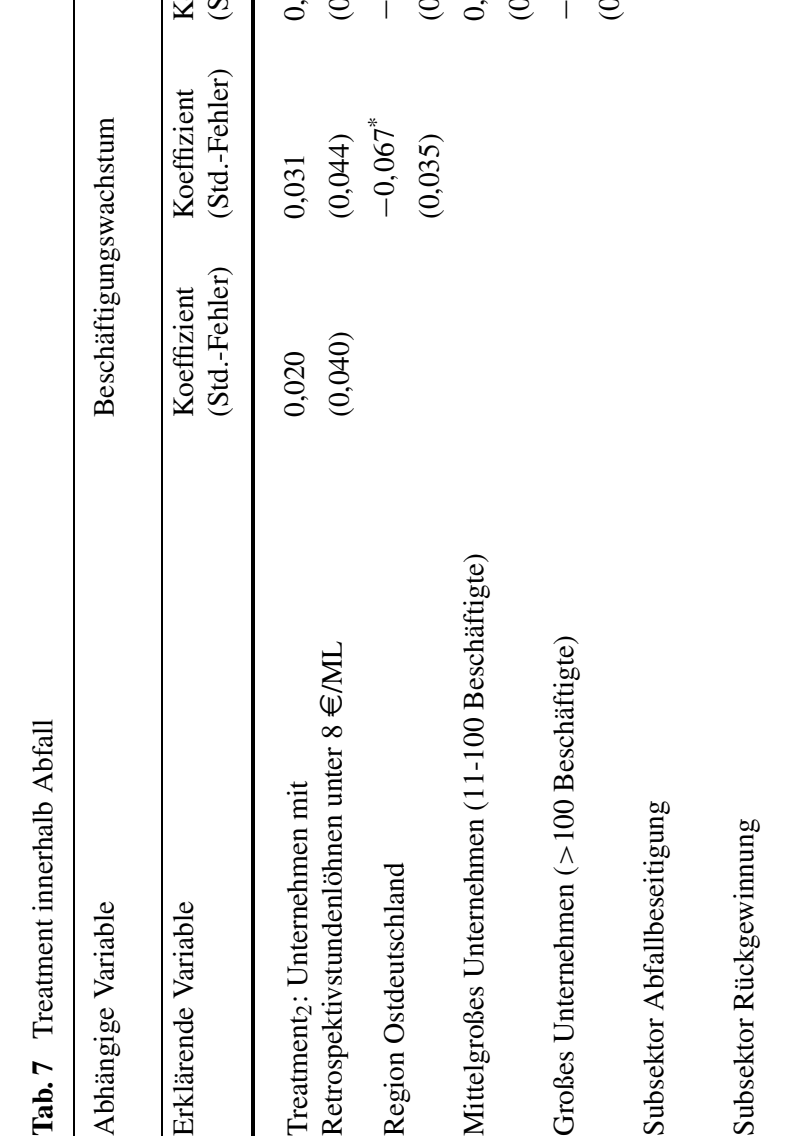

吾

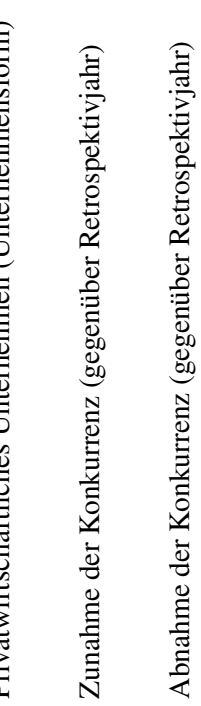

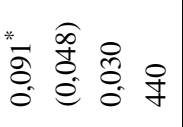

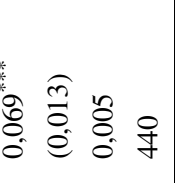

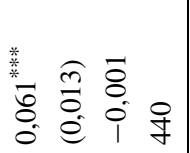

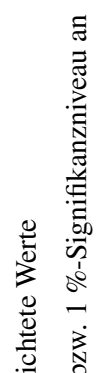




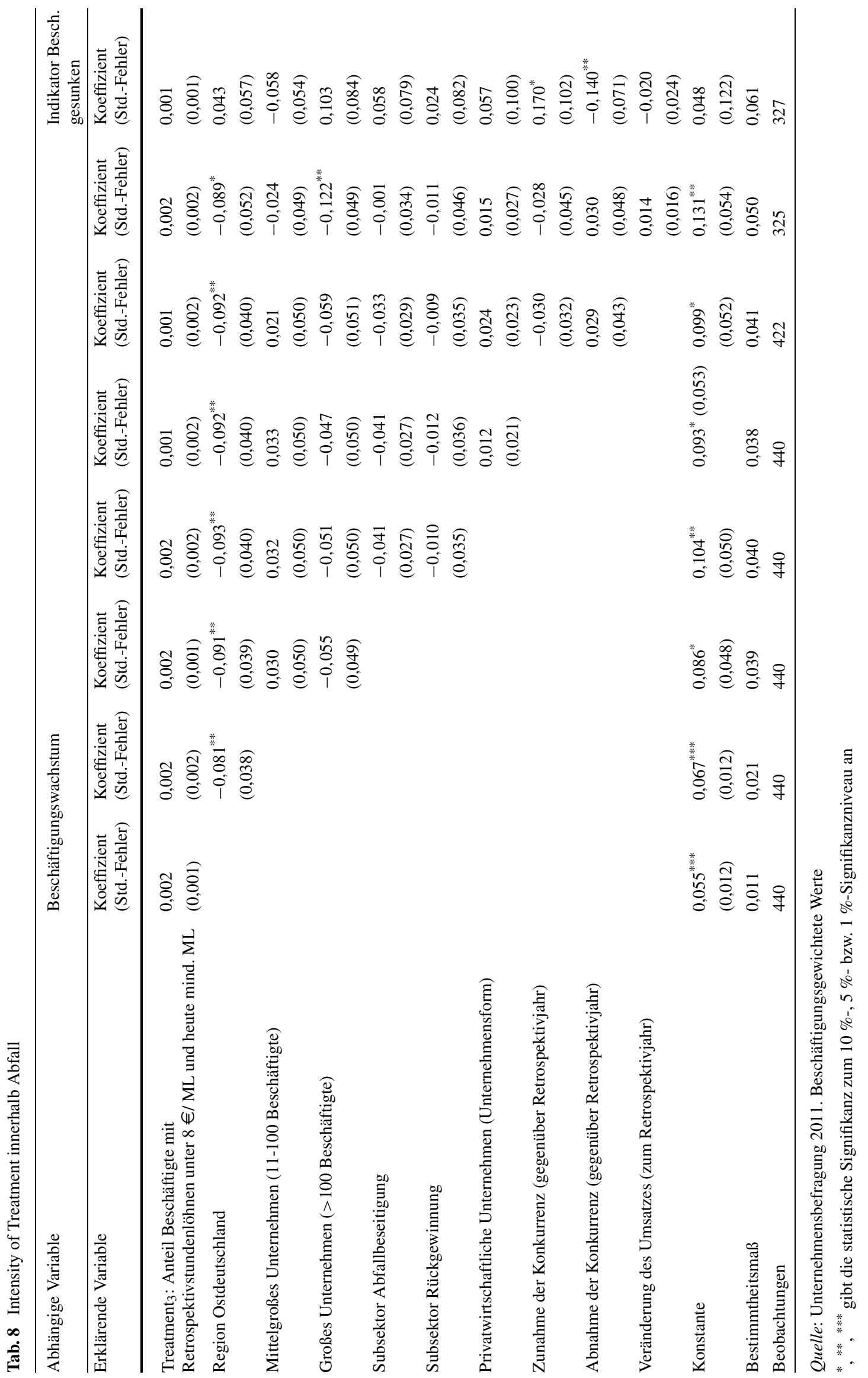




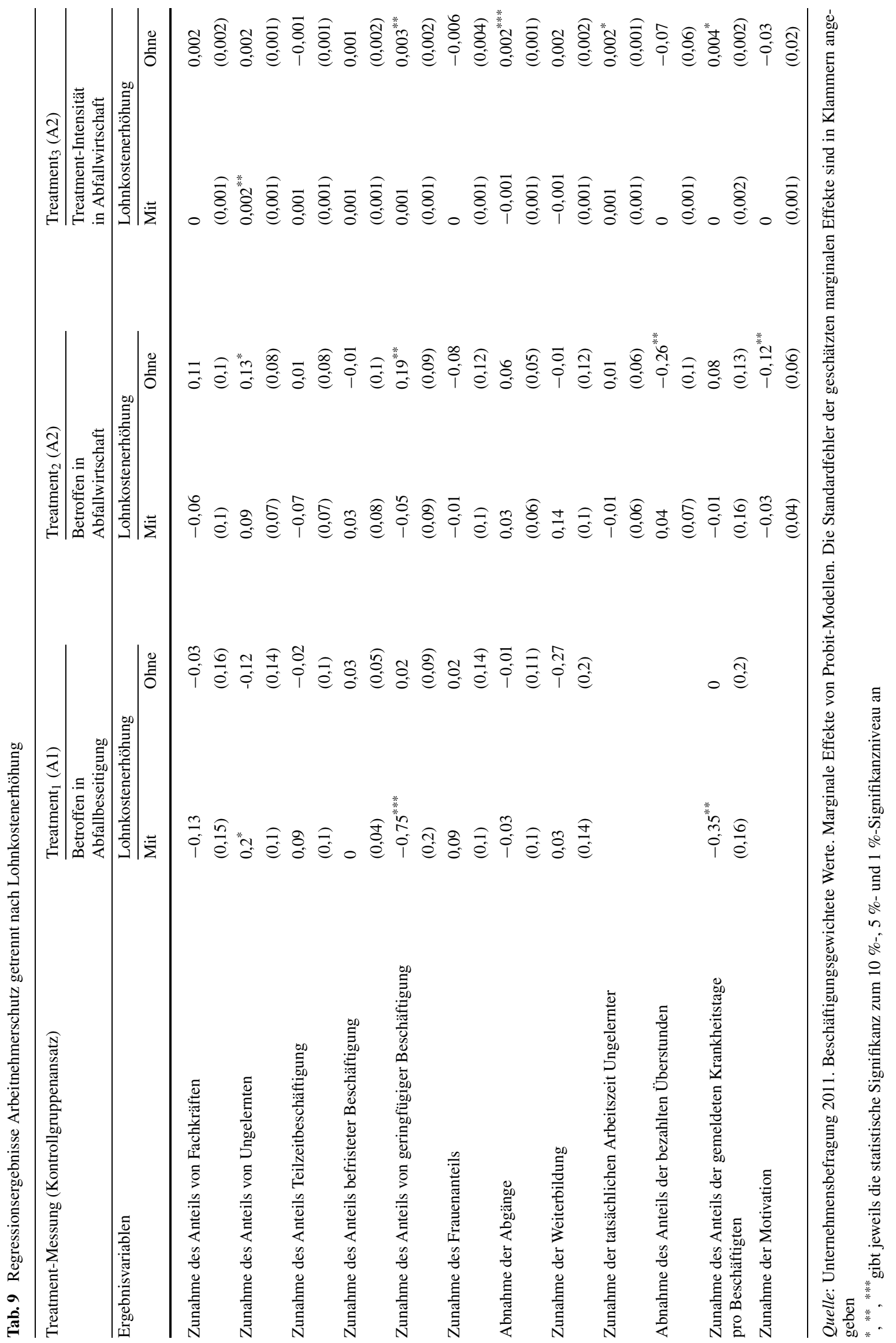




\section{Anhang B: Datenanhang}

B.1 Lohnstruktur tarifgebundener Unternehmen

Tab. 10 Unterste Tarifgruppen vor und nach der der Mindestlohneinführung

\begin{tabular}{|c|c|c|c|c|}
\hline Tarifvertrag (vor dem 1.1.2010) & \multicolumn{2}{|l|}{ Unterste Lohngruppe } & Stundenlohn West $€$ & Stundenlohn Ost $€$ \\
\hline BDE & \multicolumn{2}{|c|}{ Vergütungsgruppe 1 (VG1) } & 10,52 & 10,03 \\
\hline \multirow[t]{6}{*}{ TVöD-E } & \multirow{6}{*}{$\begin{array}{l}\text { Entgeltgruppe } \\
\text { Entwicklungsstufe }\end{array}$} & 1 & & \\
\hline & & 2 & 8,38 & 8,17 \\
\hline & & 3 & 8,53 & 8,32 \\
\hline & & 4 & 8,72 & 8,50 \\
\hline & & 5 & 8,89 & 8,67 \\
\hline & & 6 & 9,34 & 9,11 \\
\hline Tarifvertrag (ab dem 1.1.2010) & \multicolumn{2}{|l|}{ Unterste Lohngruppe } & Stundenlohn West $€$ & Stundenlohn Ost $€$ \\
\hline $\mathrm{BDE}$ & \multicolumn{2}{|c|}{ Vergütungsgruppe 1 (VG1) } & 10,52 & 10,03 \\
\hline \multirow[t]{6}{*}{ TVöD-E } & \multirow{6}{*}{$\begin{array}{l}\text { Entgeltgruppe } \\
\text { Entwicklungsstufe }\end{array}$} & 1 & & \\
\hline & & 2 & 8,48 & 8,27 \\
\hline & & 3 & 8,63 & 8,42 \\
\hline & & 4 & 8,82 & 8,60 \\
\hline & & 5 & 9,00 & 8,77 \\
\hline & & 6 & 9,46 & 9,22 \\
\hline
\end{tabular}

Quelle: Bundesentgelttarifvertrag der Abfallwirtschaft (Tarifpartner: Verdi und BDE - gültig vom 1.1.2009 bis 30.4.2010). TVöD-E (Tarifpartner: Verdi und VKA - gültig vom 1.1.2009 bis 31.12.2009 und vom 1.1.2010 bis 31.12.2010). Die Stundenlöhne wurden auf Basis der in West- und Ostdeutschland gültigen regulären wöchentlichen Arbeitszeit von 39 bzw. 40 Stunden berechnet

B.2 Geltungsbereich des Mindestlohnes und empirische Abgrenzung der Branchen über die Wirtschaftszweigklassifikation

Der im Mindestlohntarifvertrag vereinbarte Stundenlohn gilt für die gesamte Abfallwirtschaft. Nach §1 des Mindestlohntarifvertrages erstreckt sich der betriebliche Geltungsbereich auf ,... alle Betriebe der selbständigen Betriebsabteilungen, die überwiegend gewerbs- oder geschäftsmäßig Abfälle sammeln, befördern, lagern, behandeln, verwerten oder beseitigen und/oder öffentliche Verkehrsflächen reinigen“ (Mindestlohntarifvertrag Abfallwirtschaft). Gemäß §6 Abs. 8 Arbeitnehmerentsendegesetz (AEntG) betreffen "Straßenreinigung und Winterdienst" hierbei jedoch nur öffentliche Verkehrsflächen. Die Reinigung privater Verkehrsflächen einschließlich des Winterdienstes unterliegt im Gegensatz dazu der Gebäudereinigung. Für den Abfallbegriff gilt im Kontext des betrieblichen Geltungsbereichs die Definition gemäß $§ 3$ des KrW/AbfG. Hiernach sind „Abfälle im Sinne dieses Gesetzes ... alle beweglichen Sachen, die unter die in Anhang I (des $K r W / A b f G$ ) aufgeführten Gruppen fallen und deren sich ihr Besitzer entledigt, entledigen will oder entledigen muss.“
Der persönliche Geltungsbereich erstreckt sich auf ,...Arbeitnehmerinnen und Arbeitnehmer, die in Betrieben oder selbständigen Betriebsabteilungen im Sinne des Absatzes 2 tätig sind.“ (Mindestlohntarifvertrag Abfallwirtschaft).

Die in dem Beitrag dargestellten Analysen beruhen auf der Wirtschaftszweigklassifikation 2003 (WZ03) und 2008 (WZ08). Tabelle 11 und 12 (im Anhang B) liefern eine Übersicht über die Zuordnung der Wirtschaftszweigklassifikationen zu den im Folgenden untersuchten Branchen. Mit der WZ03-Klassifikation 90 zuzüglich der Klasse 37 werden für die Abfallwirtschaft inklusive der Straßenreinigung alle betrieblichen Geltungsbereiche erfasst. Bei der Straßenreinigung ergibt sich eine gewisse Unschärfe, da auf Basis der obigen Klassifikation keine separate Identifikation der Reinigung öffentlicher und privater Verkehrsflächen vorgenommen werden kann. Ebenso ist denkbar, dass im Bereich des Recyclings Unternehmen erfasst sind, die nicht unter den Mindestlohn fallen. ${ }^{18}$ Der Galabau kann eindeu-

\footnotetext{
${ }^{18}$ Dies wäre z. B. dann der Fall, wenn Unternehmen vorwiegend mit der Verwertung von bereits verarbeiteten Sekundärrohstoffen befasst
} 
Tab. 11 Wirtschaftszweigabgrenzung auf Basis der Wirtschaftszweigklassifikation 2003

\begin{tabular}{lll}
\hline Branche & WZ-Code & Beschreibung \\
\hline Abfallwirtschaft & 90.02 .1 & Sammlung, Beförderung und Zwischenlagerung von Abfällen \\
90.02 .2 & Thermische Abfallbeseitigung \\
90.02 .3 & Abfalldeponien \\
90.02 .4 & Biologische Abfallbeseitigung \\
90.02 .5 & Sonstige Abfallbeseitigung \\
& 90.03 .0 & Beseitigung von Umweltverschmutzungen und sonstige Entsorgung (inkl. Straßenreinigung) \\
& 37.00 .0 & Recycling \\
Garten- und Landschaftsbau & 01.41 .2 & Garten- und Landschaftsbau \\
\hline
\end{tabular}

Tab. 12 Wirtschaftszweigabgrenzung auf Basis der Wirtschaftszweigklassifikation 2008

\begin{tabular}{lll}
\hline Branche & WZ-Code & Beschreibung \\
\hline Abfallwirtschaft & 38.1 & Sammlung von Abfällen \\
& 38.2 & Abfallbehandlung und -beseitigung \\
& 38.3 & Rückgewinnung \\
Garten- und Landschaftsbau & 39 & Beseitigung von Umweltverschmutzungen und sonstige Entsorgung (ohne Straßenreinigung) \\
\hline
\end{tabular}

tig über den 5-stelligen WZ-Code abgegrenzt werden. Dies gilt ebenso für die WZ08 (siehe Tab. 11). Insgesamt zeigt der Vergleich der Klassifikationen, dass in der Abfallwirtschaft die Umschlüsselung von WZ03 auf WZ08 nicht eindeutig möglich ist. Das gilt sowohl für die Abfallwirtschaft insgesamt als auch für die einzelnen Unterbereiche der Abfallwirtschaft, die sich nicht zeitkonsistent den Sparten Abfallsammlung, Abfallbeseitigung, Beseitigung von Umweltverschmutzungen und sonstige Entsorgung sowie Recycling/Rückgewinnung zuordnen lassen.

\section{B.3 Amtliche Statistik}

Die amtliche Statistik bietet über verschiedene Erhebungen Daten zur Abfallwirtschaft an. Bei der Beschreibung der Entwicklung der Abfallwirtschaft und des Galabaus konzentriert sich dieser Beitrag auf Informationen aus der Umsatzsteuerstatistik, der Statistik der sozialversicherungspflichtig Beschäftigten und der Strukturerhebung im produzierenden Gewerbe bzw. im Dienstleistungsbereich.

Die Umsatzsteuerstatistik liefert Informationen zur Bestandsentwicklung, zur Umsatzentwicklung und zur Grö-

sind, die nicht mehr unter den Abfallbegriff im Sinne der strikten Definition des KrW-/AbfG fallen. In der Praxis ist jedoch davon auszugehen, dass diese Unschärfe von geringer empirischer Relevanz ist. So hat der bvse (Bundesverband Sekundärrohstoffe und Entsorgung e.V.) als Vertreter der im Recyclingbereich tätigen Unternehmen nach eigenen Angaben all seinen Mitgliedern die Anwendung des Mindestlohnes der Abfallwirtschaft empfohlen (Telefonat mit der zuständigen Justitiarin des bvse vom 09.05.2011).
Benverteilung der Unternehmen nach Umsatz. Sie stellt eine Vollerhebung aller Unternehmen mit einem jährlichen Umsatz über 17.500 Euro dar und ist weitgehend auf WZ5-Stellerebene verfügbar. So sind Informationen der Umsatzsteuerstatistik für die einzelnen Unterbranchen der Abfallwirtschaft (Sammlung von Abfällen, Abfallbeseitigung, Rückgewinnung, Beseitigung von Umweltverschmutzungen und sonstige Entsorgung) und die Kontrollbranche Galabau erhältlich. Eine Einschränkung der Umsatzsteuerstatistik besteht in ihrer mangelnden Verfügbarkeit am aktuellen Rand. Die Informationen zu einem Jahr werden erst im März des übernächsten Jahres vom Statistischen Bundesamt zur Verfügung gestellt. Im Rahmen der Evaluation konnten daher nur die Umsatzsteuerangaben bis 2009 dargestellt werden. Angaben für die Zeit nach der Mindestlohneinführung in der Abfallwirtschaft lagen nicht vor.

Anhand der Statistik der sozialversicherungspflichtig Beschäftigten lässt sich die Beschäftigtenentwicklung verfolgen. Die Daten sind ab 1999 auf WZ-3-Stellerebene bei der Bundesagentur für Arbeit (BA) online verfügbar und im Wege einer kostenpflichtigen Sonderauswertung auch auf der WZ-5-Stellerebene erhältlich.

Die jährliche Strukturerhebung im produzierenden $\mathrm{Ge}$ werbe bezieht seit 2008 maximal 7000 Unternehmen mit Schwerpunkt in der Wasserversorgung, Abwasser- und Abfallentsorgung und Beseitigung von Umweltverschmutzungen ein. Enthalten sind unter anderem Informationen zum Umsatz, zur Zahl der Beschäftigten, zur Produktivität, zum Arbeitnehmerentgelt und zur Kostenstruktur. Eine wichtige Einschränkung besteht in der eher kleinen Stichprobe und 
der Beschränkung auf Unternehmen mit bis zu einer Million Euro Umsatz im Bereich Abfallentsorgung. Die Strukturerhebung im Dienstleistungsbereich stellt die entsprechenden Informationen für den Galabau bereit. Auch diese Erhebung basiert auf einer Stichprobe.

Daneben fließen Informationen zur Entwicklung des Abfallaufkommens aus der Erhebung der Abfallentsorgung des Statistischen Bundesamtes ein. Zudem wird auf den Index der Großhandelsverkaufspreise für Altpapier, Altmetalle sowie Altmaterialien und Reststoffe des Statistischen Bundesamtes zurückgegriffen, um die Preisentwicklung auf dem Markt für Sekundärrohstoffe nachzuzeichnen, die speziell für den Bereich Rückgewinnung/Recycling relevant ist.

Die amtliche Statistik, welche die Unternehmensinformationen lediglich auf aggregierter Ebene erfasst, liefert keine direkten Maßzahlen zur Marktkonzentration. Die Verteilung der Unternehmen nach Umsatzsteuergrößenklassen und die Unternehmensdichte (Relation zwischen Unternehmensbestand und Gesamtumsatz) nach der Umsatzsteuerstatistik geben jedoch indirekt Aufschluss über die Marktkonzentration und die Wettbewerbssituation in einer Branche.

\section{B.4 CATI-Unternehmensbefragung}

Erhebung und Stichprobe Die telefonische Unternehmensbefragung zur Betroffenheit und den Konsequenzen vom Mindestlohn (CATI) wurde im Frühjahr 2010 von infas (Institut für angewandte Sozialwissenschaft, Bonn) durchgeführt. Die Erhebung baute auf einer im Jahre 2008 durchgeführten Befragung von 200 Unternehmen der Abfallwirtschaft auf.

In der Befragung 2010 wurden 752 Interviews mit Unternehmen realisiert, davon 492 in der Abfallwirtschaft und 260 im Garten- und Landschaftsbau. 148 Unternehmen wurden zum zweiten Mal befragt, davon 67 in der Abfallwirtschaft und 81 im Garten- und Landschaftsbau. Für diese so genannten Panelunternehmen liegen somit für die Variablen, die in beiden Wellen erhoben wurden, wiederholte Werte vor.

Die Datengrundlage für die CATI-Befragung bildete das Mannheimer Unternehmenspanel (MUP) des ZEW. Es wurden jeweils geschichtete Stichproben gezogen. Die Schichtung erfolgt nach der Region - West- und Ostdeutschland -, nach drei verschiedenen Unternehmensgrößenklassen - 2 bis 10 Mitarbeiter, 11 bis 100 Mitarbeiter, mehr als 100 Mitarbeiter sowie nach den Sparten der Abfallwirtschaft. Die Schichtung ermöglichte, bei der Auswertung der Befragungsergebnisse Unterschiede zwischen Ost- und Westdeutschland, den unterschiedlichen Sparten der Abfallwirtschaft sowie Unterschiede nach Unternehmensgrößen zu analysieren. Unternehmen der Abfallwirtschaft, die bereits 2007 befragt wurden, wurden prioritär kontaktiert, um möglichst viele echte Panelfälle zu erreichen. Bei Nichterfüllung der Vorgabe der zu realisierenden Interviews wurde der
Stichprobenplan im Feldverlauf der Befragung angepasst, indem zusätzliche Interviews in anderen Zellen geführt wurden.

Um die Repräsentativität der Analysen in Bezug auf die Grundgesamtheit zu gewährleisten, wurden Unternehmensgewichte konstruiert, die sich aus der inversen Auswahlwahrscheinlichkeit der Beobachtungen in jeder Zelle ergeben. D.h., jede Beobachtung wurde mit dem Verhältnis der Anzahl der Unternehmen in der Grundgesamtheit zu den Beobachtungen in der jeweiligen Zelle gewichtet. Dies hat zur Folge, dass Beobachtungen aus Zellen, die im Verhältnis zur Grundgesamtheit überproportional (unterproportional) in der Stichprobe vertreten sind, geringer (stärker) gewichtet werden. Analog wurden Gewichte konstruiert, um die Repräsentativität der Analysen im Hinblick auf die Beschäftigten zu gewährleisten. In der Wirkungsanalyse erfolgte die Gewichtung der Beobachtungen in Abhängigkeit von der Frage, ob die betrachteten Ergebnisvariablen auf Unternehmensebene oder auf Beschäftigtenebene relevant sind.

Fragenkatalog Ein erster Teil der Befragung bestand aus allgemeinen Fragen zum Unternehmen, wie z. B. zum Umsatz, zum Gründungsjahr, zum Anteil der Personalkosten an den Gesamtkosten. Ein zweiter Fragenblock widmete sich der Betroffenheit vom Mindestlohn und seinen Konsequenzen. Hier wurden zum Beispiel die Zahl der vom Mindestlohn betroffenen Mitarbeiter/innen sowie die gesetzliche Betroffenheit des Unternehmens erhoben. Darüber hinaus wurden Fragen zu sektorspezifischen Reaktionen auf eine Erhöhung der Lohnkosten eingefügt.

Zwei weitere Fragenkomplexe befassten sich mit der Beschäftigungsstruktur, der Lohnstruktur sowie mit dem Arbeitnehmerschutz und den Arbeitsbedingungen. Die hier wichtigsten erhobenen Inhalte betrafen die Anzahl der beschäftigten Personen, unterschiedliche Fragen zur Belegschaftsstruktur (Frauenanteil, Qualifikationsanteil, Anteile geringfügig Beschäftigter etc.) sowie zu Reaktionen der Arbeitsnachfrage auf eine Erhöhung der Lohnkosten (Arbeitsnachfrageelastizität). Die zum Arbeitnehmerschutz erhobenen Inhalte umfassen Fragen zur Entlohnungsstruktur, zur Arbeitszeit, dem Krankenstand, zur Fluktuation der Beschäftigten und zu etwaiger monopsonistischer Marktmacht, zur Weiterbildung sowie zur Motivation der Beschäftigten.

Retrospektiverhebung Die Abbildung der Situation vor der Einführung des Mindestlohnes erforderte die Aufnahme retrospektiver Fragen in das Befragungsinstrument. Den Referenzzeitpunkt bildete hierbei der Referenzzeitpunkt aus der Befragung 2008, die Informationen für das Jahr 2007 erhoben hat.

Die Retrospektivinformationen wurden bei allen befragten Unternehmen - also auch bei den Panelunternehmen erhoben. Dies ermöglichte es, die Zuverlässigkeit der retrospektiven Angaben überprüfen zu können und den durch die 
Retrospektivangaben verursachten Messfehler abzuschätzen. Infolge der Länge des auf den Referenzzeitpunkt bezogenen, zurückliegenden Zeitraums ist gerade bei der Angabe von Absolutwerten bei den Retrospektivinformationen mit einem erheblichen Erinnerungsfehler (Recall-Error) zu rechnen. Aus diesem Grunde wurden bei einigen Retrospektivinformationen keine absoluten Veränderungswerte, sondern vielmehr eine Einschätzung über die $\mathrm{Zu}$ - oder $\mathrm{Ab}$ nahme der entsprechenden Zielgrößen gegenüber dem Referenzzeitpunkt 2007 abgefragt. Für Schlüsselvariablen wie die Beschäftigtenzahl oder den Umsatz wurde jedoch die eingeschätzte Veränderung des absoluten Wertes erhoben. Insgesamt deutet die Untersuchung des Retrospektivfehlers auf einen erheblichen Messfehler vor allem bei der Entwicklung der Beschäftigung hin, während die Fragen zur Lohnstruktur als zentrale erklärende Variablen der Untersuchung mit einem geringeren Messfehler behaftet sind. Nähere Details hierzu finden sich im Evaluationsbericht Egeln et al. (2011).

\section{Literatur}

Berninger, B., Kohlmeyer, R.: Effekte der Abwrackprämie auf Autoverwerter. Umwelt Mag. 6, 12-13 (2009)

Borjas, G.: Labor Economics. McGraw-Hill, Boston (2010)

Cahuc, P., Zylberberg, A.: Labor Economics. MIT Press, Cambridge (2004)

Cameron, A.C., Trivedi, P.K.: Microeconometrics. Methods and Applications. Cambridge University Press, Cambridge (2005)

Card, D.: Using regional variation in wages to measure the effects of the federal minimum wage. Ind. Labor Relat. Rev. 1, 22-37 (1992)

Egeln, J., Gottschalk, S., Gürtzgen, N., Niefert, M., Rammer, C., Sprietsma, M., Schröder, H., Schütz, H.: ZEW-Studie zu den Wirkungen eines Mindestlohns in der Abfallwirtschaft, Auftraggeber BMAS (2011)

Ellguth, P., Kohaut, S.: Tarifbindung und betriebliche Interessenvertretung - Aktuelle Ergebnisse aus dem IAB-Betriebspanel 2010. WSI-Mitt. 64, 242-247 (2011)

Finanzgruppe Branchendienst: Branchenreport Recycling und Umwelttechnik 2010, WZ-Code 38 (2010)

Katz, L.F., Krueger, A.B.: The effect of the minimum wage on the fast food industry. Ind. Labor Relat. Rev. 1, 6-21 (1992)
König, M., Möller, J.: Mindestlohneffekte des Entsendegesetzes. Z. Arb.markt Forsch. 2/3, 328-345 (2008)

Manning, A.: The real thin theory: monopsony in modern labour markets. Labour Econ. 10, 105-131 (2003)

Neumark, D., Wascher, W.: Employment effects of minimum and subminimum wages: panel data on state minimum wage laws. Ind. Labor Relat. Rev. 46, 55-81 (1992)

Neumark, D., Wascher, W.: Minimum wages and employment. Found. Trends Microecon. 3, 1-182 (2007)

Info, V.R.: Garten- und Landschaftsbau. In: VolksbankenRaiffeisenbanken. Brancher special Bd. 59. ifo-Institut, München (2005)

Nicole Gürtzgen holds a position as a Senior Researcher in the department "Labour Markets, Social Policy and Human Resources" at the Centre for European Economic Research (ZEW) in Mannheim. After graduating from the University of Heidelberg in economics, she completed her doctoral dissertation on "Product Market Integration and Collective Bargaining Outcomes in Unionised Oligopolistic Industries" at the University of Rostock in 2002. In 2008, she finished her postdoctoral thesis (Habilitation) "Essays on Collective Bargaining Coverage, Wage Determination and Employment Dynamics in Germany" at the University of Mannheim.

Maresa Sprietsma holds a position as a Post-Doc Researcher in the department "Labour Markets, Social Policy and Human Resources" at the Centre for European Economic Research (ZEW) in Mannheim since 2006. After the obtention of a Msc in economics from the Katholieke Universiteit Leuven (Belgium), she completed her doctoral dissertation titled "Improving Student Performance: 3 Microeconometric Studies" at the Université Catholique de Louvain in 2007.

Michaela Niefert studied Economics at the universities of Mainz and Bielefeld. Her studies focused on econometrics and empirical economic research. From 1997 to 2003 she was a research and teaching assistant at the chair for Economic Policy, University of Bielefeld, and at the chair for Social Policy and Public Economics, Ruhr-Universität Bochum. She completed her doctoral thesis on mobility and housing choice in July 2003. She joined the ZEW research department "Industrial Economics and International Management" in April 2003. Her research centres on entrepreneurship and small and medium sized enterprises.

Sandra Gottschalk studied Economics at the University of Bielefeld majoring in econometrics and empirical economic research. She is a Senior Researcher at the ZEW research department "Industrial Economics and International Management". Her research focuses on topics concerning the founding and closing of enterprises. In particular, she analyses the influence of the founder's human capital on performance, development and the probability of closing of start-up enterprises. 